\title{
The central nervous system transcriptome of the weakly electric brown ghost knifefish (Apteronotus leptorhynchus): de novo assembly, annotation, and proteomics validation
}

Joseph P Salisbury ${ }^{1}$, Ruxandra F Sîrbulescu², Benjamin M Moran², Jared R Auclair ${ }^{1}$, Günther KH Zupanc ${ }^{2^{*}}$ and Jeffrey $N$ Agar $^{1,3^{*}}$

\begin{abstract}
Background: The brown ghost knifefish (Apteronotus leptorhynchus) is a weakly electric teleost fish of particular interest as a versatile model system for a variety of research areas in neuroscience and biology. The comprehensive information available on the neurophysiology and neuroanatomy of this organism has enabled significant advances in such areas as the study of the neural basis of behavior, the development of adult-born neurons in the central nervous system and their involvement in the regeneration of nervous tissue, as well as brain aging and senescence. Despite substantial scientific interest in this species, no genomic resources are currently available.

Results: Here, we report the de novo assembly and annotation of the A. leptorhynchus transcriptome. After evaluating several trimming and transcript reconstruction strategies, de novo assembly using Trinity uncovered 42,459 unique contigs containing at least a partial protein-coding sequence based on alignment to a reference set of known Actinopterygii sequences. As many as 11,847 of these contigs contained full or near-full length protein sequences, providing broad coverage of the proteome. A variety of non-coding RNA sequences were also identified and annotated, including conserved long intergenic non-coding RNA and other long non-coding RNA observed previously to be expressed in adult zebrafish (Danio rerio) brain, as well as a variety of miRNA, snRNA, and snoRNA. Shotgun proteomics confirmed translation of open reading frames from over 2,000 transcripts, including alternative splice variants. Assignment of tandem mass spectra was greatly improved by use of the assembly compared to databases of sequences from closely related organisms. The assembly and raw reads have been deposited at DDBJ/EMBL/GenBank under the accession number GBKR00000000. Tandem mass spectrometry data is available via ProteomeXchange with identifier PXD001285.
\end{abstract}

Conclusions: Presented here is the first release of an annotated de novo transcriptome assembly from Apteronotus leptorhynchus, providing a broad overview of RNA expressed in central nervous system tissue. The assembly, which includes substantial coverage of a wide variety of both protein coding and non-coding transcripts, will allow the development of better tools to understand the mechanisms underlying unique characteristics of the knifefish model system, such as their tremendous regenerative capacity and negligible brain senescence.

Keywords: De novo transcriptome, RNA-Seq, Brain, Spinal cord, Apteronotus leptorhynchus, Brown ghost knifefish, Proteomics, Non-coding RNA, Splice-junction peptides

\footnotetext{
* Correspondence: g.zupanc@neu.edu; j.agar@neu.edu

2Laboratory of Neurobiology, Department of Biology, Northeastern University,

360 Huntington Avenue, 134 Mugar Life Sciences, Boston, MA 02115, USA

'Barnett Institute, Department of Chemistry and Chemical Biology, Northeastern

University, 360 Huntington Avenue, 412 TF, Boston, MA 02115, USA

Full list of author information is available at the end of the article
} 


\section{Background}

The brown ghost knifefish (Apteronotus leptorhynchus) is a weakly electric teleost fish belonging to the taxonomic order Gymnotiformes. This species has been widely studied over the past several decades as a model system in a variety of disciplines within biology and neuroscience, with particular focus on the ionic and neuromodulatory regulation of neural oscillations [1-6], neural control of communication via electric signals $[7,8]$, and central nervous system (CNS) regeneration $[9,10]$.

Most research involving this species has addressed diverse aspects of their nervous system. As all other species of the family Apteronotidae, A. leptorhynchus generates electric discharges using a neurogenic electric organ, formed by modified axonal terminals of spinal motoneurons [11]. The electric organ discharge is used for orientation and object detection in close vicinity of the fish $[12,13]$, and for communication with conspecifics [7,14-19]. Knifefish are able to sense both their own electric discharges and electric signals of other biological and non-biological sources through electroreceptors distributed on the skin $[8,20,21]$. The neural structures involved in the processing of behaviorally relevant electrosensory information, and in the motor control of the electric organ discharges, are among the best characterized brain and spinal cord systems of any non-mammalian vertebrate, thus establishing A. leptorhynchus as a significant model of neuroethology [22].

These neuroethological investigations have yielded an extensive body of information on the structure and function of the CNS of A. leptorhynchus, including the first neuroanatomical atlas of the brain of any teleost species [23]. This knowledge base has, in turn, encouraged the use of the brown ghost knifefish as a model organism in several other biological disciplines, including developmental neurobiology and regenerative biology. For example, the availability of a brain atlas enabled the first comprehensive mapping of adult-born cells in the whole brain of any vertebrate species [24], establishing A. leptorhynchus as a major teleostean model system for the study of adult neurogenesis $[9,10,25,26]$, and informing similar mappings of the stem cell niches in the adult brain of zebrafish (Danio rerio) [27] and the Mozambique tilapia (Oreochromis mossambicus) [28]. Utilization of this model has provided substantial insight into the cellular mechanisms that underlie the generation, migration, and differentiation of adult-born cells in various regions of the CNS [29-33]. Recently, $A$. leptorhynchus has been introduced to the area of aging research as the first vertebrate model system exhibiting negligible brain senescence [34].

Like many other teleost fish studied thus far, apteronotids have a remarkable capacity for regeneration after CNS injury, a property which has been connected to the high levels of adult neurogenesis occurring throughout the life of fish [10]. Adult neurogenesis and neuroregeneration have been studied extensively both in the brain and in the spinal cord of brown ghost knifefish. Studies using proteomic analysis in conjunction with brain lesion paradigms have contributed to a better understanding of the molecular dynamics triggered by injury and subsequent regeneration $[35,36]$.

The unique neurogenic origin of the electric organ in apteronotids greatly facilitates the correlation of structural regeneration and functional recovery after spinal cord injuries, by allowing instantaneous non-invasive monitoring of the activity of newly formed spinal electromotor neurons. Thus, the spinal cord of brown ghost knifefish has proven to be a useful model both for understanding spontaneous regeneration of the CNS and for assessing the effectiveness of experimental manipulations aimed at improving natural recovery in regeneration-competent organisms [37-40].

Despite the extensive use of apteronotids as model systems, there are currently no large-scale genomic resources for any species of this family. Several studies have used molecular cloning and sequencing to determine partial or complete sequences of less than two dozen proteins, mostly transmembrane ion channels and receptors [41-54], but also synaptic scaffold proteins [55], enzymes [56], and homeobox genes [57]. The addition of new, detailed sequence information on a large scale is required for the development of better tools to be used in the study of the CNS in knifefish.

The present investigation describes the de novo assembly and annotation of the A. leptorhynchus CNS transcriptome based on sequencing datasets derived from Illumina-based sequencing-by-synthesis. Results are presented for libraries prepared from both the brain and the spinal cord of ten adult male and female knifefish. Translation of a subset of transcript open reading frames was experimentally validated by shotgun proteomics.

\section{Results and discussion}

Given the lack of a reference A. leptorhynchus genome, we adopted a de novo assembly and annotation strategy to evaluate assembly quality and interpret results (Figure 1A). Since complete genome sequences are available for a number of fish species, this existing information can be used to examine the quality of the presented de novo assembly, and to annotate it. Such genomic information is currently available for two species of pufferfish, the Japanese pufferfish (Takifugu [Fugu] rubripes), the first vertebrate genome to be released after the human one [58], and the spotted green pufferfish (Tetraodon nigroviridis) [59]; as well as for the medaka (Oryzias latipes) [60]; the Atlantic cod (Gadus morhua) [61]; the three-spined stickleback (Gasterosteus aculeatus) [62]; the zebrafish (D. rerio) [63]; the Southern platyfish (Xiphophorus maculatus) [64]; and, recently, the coelacanth (Latimeria chalumnae) [65]. Out of all teleost fish with complete genomes available, the only 


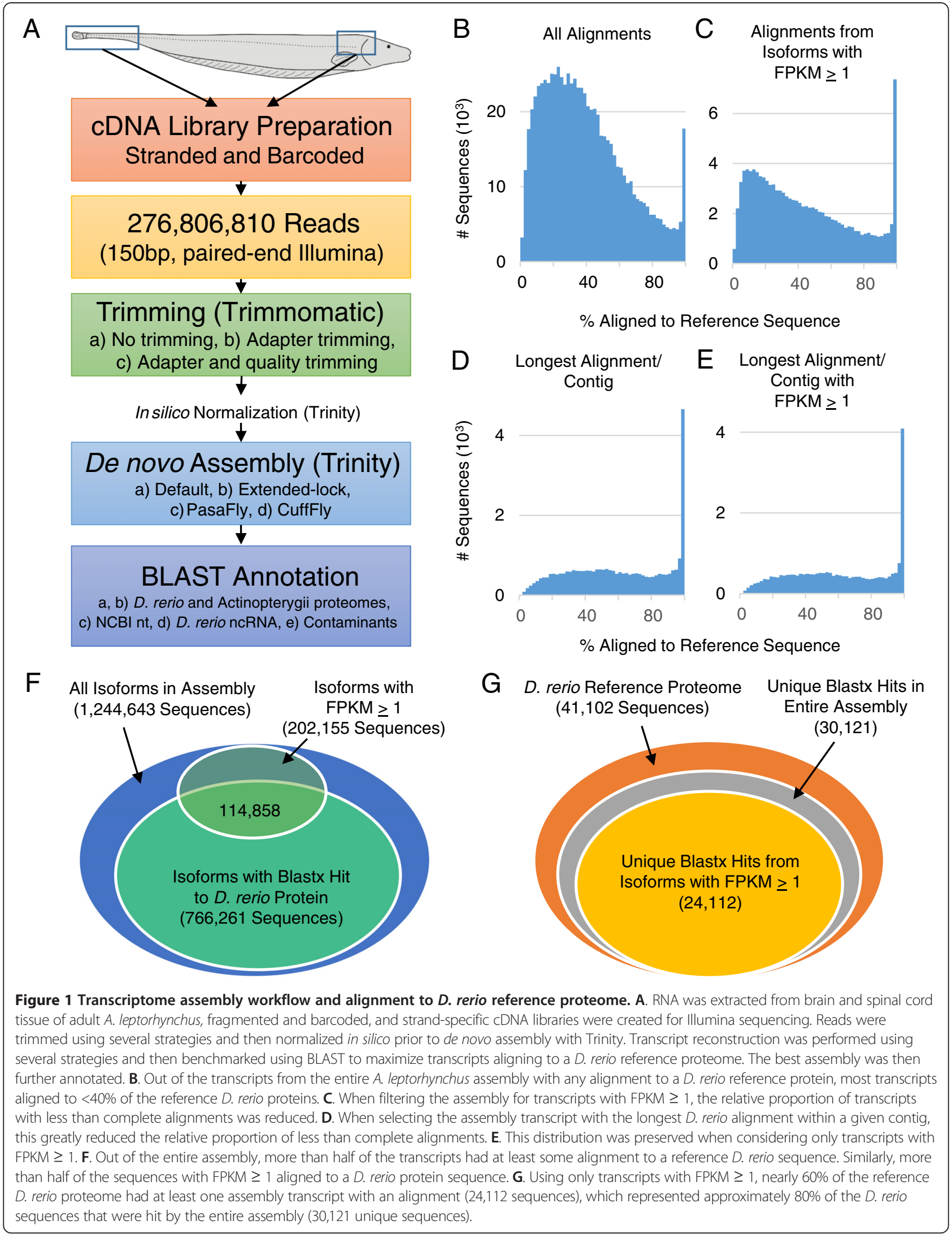


species that belongs to the same phylogenetic superorder (Ostariophysi) and subdivision (Otocephala) as A. leptorhynchus, is D. rerio [66,67]. Similarly, D. rerio is the species most closely related to A. leptorhynchus, according to established phylogenetics, for which a complete reference proteome sequence set is available. We therefore preferentially used the genomic and proteomic information available from $D$. rerio as a reference for sequence comparison and for de novo transcriptome annotation in A. leptorhynchus. This approach further allowed us to leverage the power of several bioinformatics tools often only available for the core model species.

\section{De novo transcriptome assembly}

Strand-specific cDNA libraries were prepared from CNS tissues (brain and spinal cord) of 10 adult male and female A. leptorhynchus. Final raw read counts included 24,164,311, 150 bp paired-end reads passing filter on an Illumina MiSeq platform, and 252,642,499 150 bp paired-end reads passing filter obtained using an Illumina HiSeq 2500 platform. These reads were combined and then assembled using Trinity [68]. After optimizing parameters for trimming and transcript reconstruction (see below), an assembly with $\sim 300,000$ unique contigs, including $\sim 1.2 \mathrm{M}$ total isoforms, was produced. Of these, 42,459 contigs contained at least a partial protein-coding sequence based on alignment to a reference set of known Actinopterygii protein sequences. As many as 11,847 of these contigs contained full or near-full length $(\geq 80 \%)$ unique protein sequences (based on significant sense alignments to the Actinopterygii reference set, described below), thus providing broad coverage of the A. leptorhynchus proteome. In general, we used BLAST alignment of transcripts (or translations of predicted ORFs from transcripts) to reference protein sets as a means of assessing coding transcript completeness. Transcripts with $\geq$ $80 \%$ sequence coverage (i.e. a significant alignment between a transcript sequence from our assembly and a target protein sequence, where the alignment covers at least $80 \%$ of the target protein sequence) are thus considered "full or near-full length".

\section{Trimming optimization}

As part of optimizing our de novo assembly, we compared the effect of read trimming on de novo transcriptome assembly. Read trimming strategy affects assembly quality and can impact downstream analysis, with the best tradeoff between read loss and dataset quality dependent upon the dataset itself as well as research goals [69]. For trimming reads prior to assembly, we evaluated no trimming, "soft" trimming, where 3' adapter sequences present from insert read-through during sequencing were removed as well as leading and trailing bases that were uncalled ("N" bases) or with low quality (below 3), and "hard" trimming, where, in addition to the "soft" trimming criteria, a sliding window was used to eliminate bases that fall below a threshold quality (4-base wide sliding window, cutting when the average quality per base dropped below 15 $[70,71])$. In either of the trimmed read sets, trimmed sequences shorter than 35 bp were also removed before further analysis, as well as reads that became unpaired because of this. Prior to assembly, these trimmed read sets were pooled and normalized using the in silico normalization script packaged with Trinity, in order to remove highly redundant sequences and reduce assembly computational time. The trimmed, normalized read sets were then assembled with Trinity using the default settings for strandspecific, paired-end read sets, including a $200 \mathrm{bp}$ minimum transcript length (additional parameters for transcript reconstruction were considered and are described below). Trinity produces transcripts that are assigned to 'genes' (previously referred to in Trinity as "components"), with each gene set potentially corresponding to multiple transcripts derived from the same genomic loci (i.e. transcripts within the same assembly gene are potential alternatively spliced variants). Here, we refer to unique Trinity "components" as "contigs", where a single contig can include a set of multiple sequence variants.

In order to compare quality of assembly methods and permit further optimization, we BLASTx searched (E-value cut-off $\left.=10^{-5}\right)$ a $D$. rerio reference proteome $(41,112$ sequences) obtained from UniProtKB, which contained nonredundant sequences from both SwissProt and Trembl. Relative to the total number of protein sequences in this $D$. rerio reference proteome set, similar coverage was achieved regardless of trimming strategy, although the "soft" trimming strategy provided a minor advantage over "hard" trimming, recovering $2.44 \%$ more transcripts with at least $80 \%$ sequence coverage $(12,446$ sequences, including antisense alignments, for soft trimming compared with 12,149 sequences for hard trimming) (Additional file 1: Figure S1A). It has been reported that while the aggressive qualitybased trimming strategy is common, a gentler strategy can favor increasing sensitivity of transcript reconstruction during de novo assembly [72].

Regardless of trimming strategy, each raw assembly was considerably large, with $\sim 300,000$ contigs and $\sim 1.2 \mathrm{M}$ total isoforms per assembly. Whereas these values were similar to the numbers observed using comparable methods [73,74], they are larger than more reasonable estimates of loci achieved with other datasets [75]. This may be due to incomplete contiguous transcript reconstruction of low-expressed transcripts, resulting in multiple (nonoverlapping) contigs per locus, as well as contamination and transcriptional noise. We attempted to determine whether the size of the assembly could be further limited, while retaining coverage of the $D$. rerio proteome, by evaluating different strategies for transcript reconstruction. 


\section{Transcript reconstruction optimization}

With the goal of minimizing excessive alternative transcript reconstruction, we evaluated several reconstruction methods in Trinity. Aside from the default Trinity transcript reconstruction method, Butterfly [76], we considered Butterfly in "extended lock" mode, which favors more conservative transcript reconstruction resulting in fewer isoforms. In addition, CuffFly, an implementation of the Cufflinks assembly algorithm [74,77] that finds the minimum number of isoforms that capture the variation in the reads, and PasaFly, an implementation of the PASA (Program to Assemble Spliced Alignments) assembly algorithm [78] adapted for Butterfly transcript graphs, were also evaluated, as these methods generally tend to produce even more conservative isoform reconstructions. While the alternative transcript reconstruction methods reduced the overall number of transcripts in the assembly, they produced similar number of overall contigs (Additional file 1: Figure S1B). Despite similar number of contigs overall, the default (Butterfly) transcript reconstruction did provide some enhanced sensitivity, with $7.98 \%$ more sequences aligned than the next best reconstruction method (12,446 sequences, including antisense alignments, covered with Butterfly compared with 11,526 with PasaFly) (Additional file 1: Figure S1C).

Overall, while many contigs remained unassigned at this initial level of annotation, the identification of contigs with sense alignments covering $\geq 80 \%$ of 9901 D. rerio protein sequences indicated that the assembly was of substantial quality (Additional file 2: Table S1) despite being limited to libraries prepared from only the CNS of $A$. leptorhynchus. The large number of assembly contigs with only partial alignments suggested that higher coverage could be achieved with additional libraries from other tissues.

\section{Full sequence coverage enrichment amongst highly expressed transcripts}

From the assembly produced by the least stringent but most sensitive Butterfly method, the number of isoforms per contig followed a power law, with many contigs having few isoforms and a few contigs having many (100-1000) isoforms (Additional file 1: Figure S1D). However, after filtering for transcripts with number of fragments per kilobase of transcript per million mapped reads (FPKM) $\geq 1$, the approximate equivalent of 1 transcript per cell [79], the number of transcripts per contig was reduced to a log distribution, where even though many contigs had multiple isoforms, the number of isoforms was on the order of 10's (Additional file 1: Figure S1E). In terms of transcript length, the overall assembly had a N50 of 2539 bp (median transcript length $=1219 \mathrm{bp}$, average length $=1606 \mathrm{bp}$, total assembled bases $=\sim 2.0 \mathrm{~Gb}$, Additional file 1: Figure S1F). However, when considering only the longest transcripts per assembly contig, the distribution shifted to an N50 of
$940 \mathrm{bp}$ (median transcript length $=377 \mathrm{bp}$, average length $=$ $661 \mathrm{bp}$, total assembled bases $=\sim 230 \mathrm{Mb}$, Additional file 1: Figure S1G), suggesting that the larger N50 calculated from the entire assembly (including every isoform per contig) was due to longer contigs having many long isoforms assembled by Trinity. After filtering for transcripts with FPKM $\geq 1$, the N50 was 2093 bp (median transcript length $=1140$ bp, average length $=1508 \mathrm{bp}$, total assembled bases $=\sim 303 \mathrm{Mb}$ Additional file 1: Figure $\mathrm{S} 1 \mathrm{H}$ ), with a more consistent (i.e. less biased) N50 of $1995 \mathrm{bp}$ (median transcript length $=907 \mathrm{bp}$, average length $=1330 \mathrm{bp}$, total assembled bases $=\sim 110 \mathrm{Mb}$ ) after considering only the longest transcript per contig (Additional file 1: Figure S1I). Thus, when considering only contigs with isoforms that had an FPKM $\geq 1$, the overall distribution of transcript size was improved.

Out of all 766,261 transcripts from the assembly (including variant isoforms belonging to the same contig) with an alignment to a $D$. rerio reference protein, most transcripts aligned to $<40 \%$ of the respective protein (Figure 1B). When filtering the assembly for transcripts with FPKM $\geq 1$, the relative proportion of transcripts with less than complete alignments was reduced (Figure $1 \mathrm{C}$ ). When selecting only the longest aligned transcript per contig, the relative proportion of shorter alignments was reduced (Figure 1D), suggesting many assembly transcripts within a contig group contained partial open reading frames (ORFs). This distribution was preserved when considering only the longest aligned transcript per contig that also had an FPKM $\geq 1$ (Figure 1E). Out of the entire assembly, more than half of the transcripts had at least some alignment to a reference $D$. rerio sequence. Likewise, more than half of the sequences with FPKM $\geq 1$ aligned to a $D$. rerio protein sequence (Figure $1 \mathrm{~F}$ ). Using only transcripts with FPKM $\geq 1$, nearly $60 \%$ of the reference $D$. rerio proteome had at least one assembly transcript with an alignment $(24,112$ sequences), which represented $\sim 80 \%$ of the $D$. rerio sequences that were hit by the entire assembly $(30,121$ unique sequences, Figure 1G).

\section{Enrichment of sequences aligning to closely related fish species}

$D$. rerio has become one of the dominant model fish species in developmental biology, and leveraging the high quality annotation developed for this fish species makes it an attractive dataset to build from in annotating the A. leptorhynchus transcriptome. However, as described earlier, genomic studies of several fish species exist, leading to several "complete" reference proteomes being established. To assess the relative applicability of various wellcharacterized fish species' sequence data, we aligned the assembly to a well-annotated proteome sequence set consisting of seven species, including $D$. rerio, the Nile tilapia 
(Oreochromis niloticus), X. maculatus, G. aculeatus, O. latipes, T. rubripes, and T. nigroviridis. While the overall number of transcripts with significant alignments increased in this expanded sequence set, the majority of highest identity protein-coding sequences in the A. leptorhynchus transcriptome were found to align to sequences from $D$. rerio (Table 1), consistent with known phylogenetic relations between these fish species [67]. In total, 11,847 contigs had sense alignments that covered $\geq 80 \%$ of an Actinopterygii protein sequence (Additional file 3: Table S2).

To investigate the quality of the A. leptorhynchus assembly by alignment to a broader set of transcript sequences, the assembly sequences were BLASTn searched against the entire NCBI nt sequence set (E-value cut-off $=10^{-5}$ ). Sorting the BLASTn results by species showed an overwhelming representation of fishes, with the best represented species being the characiform Astyanax mexicanus (Mexican tetra, blind cave fish), followed by the wellcharacterized cypriniform $D$. rerio (Figure 2). This finding is not surprising given that these two species belong to the same taxonomic superorder, Ostariophysi. On the other hand, one would have expected more hits to the A. leptorhynchus assembly among two other ostariophysans, the siluriforms Ictalurus punctatus (channel catfish) and Ictalurus furcatus (blue catfish). However, this result is likely influenced by the relative abundance of the high-quality sequences available for both $D$. rerio and $A$. mexicanus $[80,81]$.

Transcriptome coverage assessment and enrichment analysis To provide a detailed view of the coverage of the assembly in terms of diversity of protein-coding transcripts assembled, we examined the percent of genes covered by Gene Ontology (GO) categories based upon existing annotation from $D$. rerio (using the corresponding gene names for proteins in the $D$. rerio reference protein sequence set). Using a generic set of GO-slim categories, we evaluated both the set of $D$. rerio protein sequences that were covered at least $80 \%$ by a sense-aligned $A$. leptorhynchus assembly sequence, as well as the set of $D$. rerio proteins that had any significant alignment to $A$. leptorhynchus assembly sequences (Figure 3A-C). While the set of $D$. rerio genes with at least partial alignments indicates that over $90 \%$ of genes in any given GO class have been identified, it remains possible that some of these incomplete alignments could be spurious or misassembled artifacts. Thus, the coverage of the more fully resolved genes can be considered a more accurate read-out of the A. leptorhynchus assembly coverage. Overall transcriptome coverage was balanced across major structural and functional categories. Notably, in terms of cellular components, the ribosome had the highest percentage (90\%) of transcripts that were full or near-full length. This was also observed when looking at the percentage of contigs covered in major pathways from the Kyoto Encyclopedia of Genes and Genomes (KEGG) database [83,84] (Figure 3D).

The moderate-to-low coverage of many genes can be partially attributed to tissue/life stage-specific and/or weakly expressed gene transcripts. To test this hypothesis, we used the Zebrafish Expression Ontology of Gene Sets (ZEOGS), a tool that determines which anatomical structures are overrepresented in a given input gene set [85]. Indeed, when examining enrichment of adult $D$. rerio genes that had over $80 \%$ sequence coverage by $A$. leptorhynchus assembly transcripts, a variety of nervous systemrelated terms, including central nervous system, spinal cord, optic tectum, epiphysis, etc., were significantly enriched (Benjamini-Hochberg adjusted $p<0.05$, Table 2). By contrast, the set of $D$. rerio sequences with low-to-no sequence coverage in the $A$. leptorhynchus assembly were significantly enriched for various other anatomical terms, including components of the reproductive and skeletal systems as well as the heart. This method of classification could be used in future analyses to help prioritize tissues for library preparation and sequencing to further expand transcriptome coverage.

To assess which molecular categories were most highly expressed among those transcripts of the A. leptorhynchus

Table 1 Coverage of proteins for Actinopterygii species by relative number of entries in reference sets

\begin{tabular}{lll}
\hline Binomial name & Common name & Hits/Total (\% of Total/\% Relative) \\
\hline Danio rerio & Zebrafish & $7880 / 41102(66.5 \% / 56.1 \%)$ \\
Oreochromis niloticus & Nile tilapia & $1257 / 26753(10.6 \% / 13.7 \%)$ \\
Xiphophorus maculatus & Southern platyfish & $654 / 20451(5.5 \% / 9.4 \%)$ \\
Gasterosteus aculeatus & Three-spined stickleback & $607 / 27248(5.1 \% / 6.5 \%)$ \\
Oryzias latipes & Japanese rice fish & $525 / 24637(4.4 \% / 6.2 \%)$ \\
Takifugu rubripes (Fugu rubripes) & Japanese pufferfish & $549 / 47867(4.6 \% / 3.4 \%)$ \\
Tetraodon nigroviridis & Spotted green pufferfish & $375 / 23073(3.2 \% / 4.8 \%)$ \\
All species & & $11847 / 211131$ sequences \\
\hline
\end{tabular}

"\% of Total" is percent of sequences out of total number of sequences across all 7 reference protein sequence sets. "\% Relative" is percent of sequences normalized by the proportion of sequences from that species out of the 7 reference protein sequence sets examined. Only alignments that covered $\geq 80 \%$ of the reference protein are included in this analysis. 


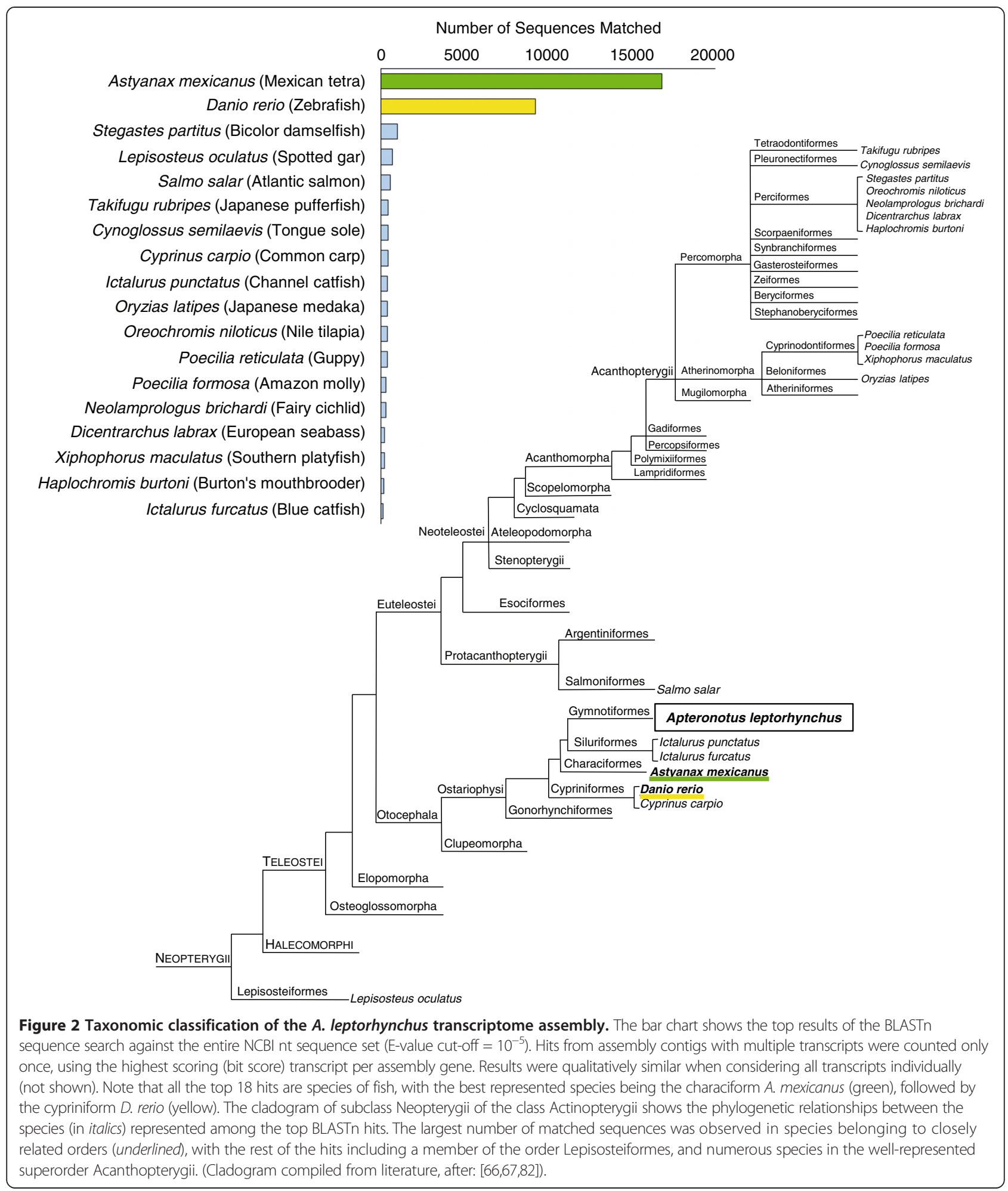

assembly that aligned to $\geq 80 \%$ of a reference $D$. rerio protein, assembly transcripts were first ranked by FPKM, and the GO classification for the corresponding $D$. rerio genes was used to determine enrichment of the most highly expressed transcripts using GOrilla [86]. GOrilla uses the variable enrichment thresholding method of minimum hypergeometric scoring to determine $\mathrm{GO}$ enrichment from ranked gene lists, with significantly enriched GO categories found on average in the top $9.6 \%$ of genes (4.8\% S.D.). When considering the relative expression 


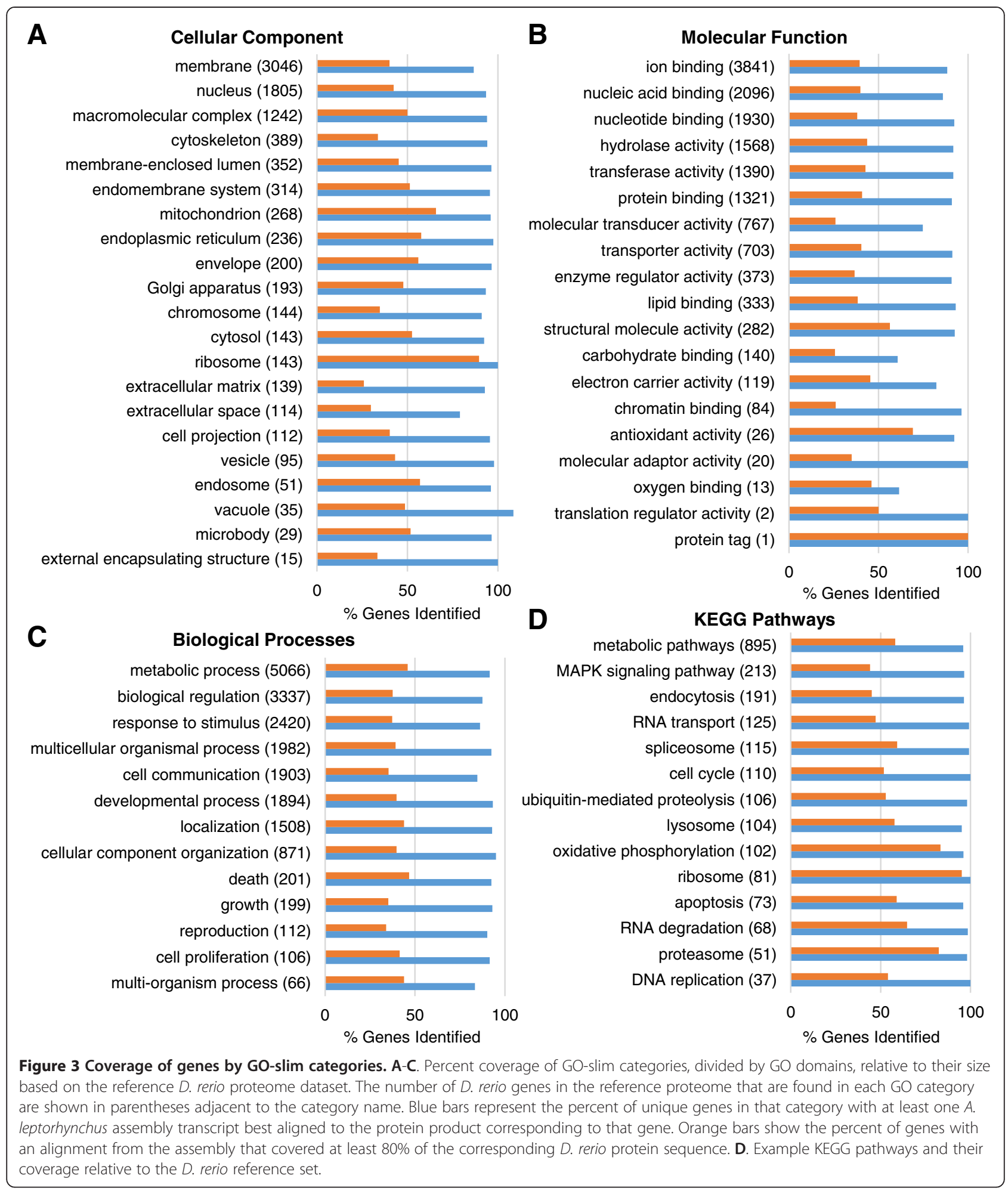

levels of transcripts with full or near-fully resolved ORFs, structural components of the ribosome and factors involved in translation were found to be most prominent (Figure 4, Additional file 4: Table S3), consistent with the observation that the ribosome was the cellular component that had the highest percentage of well-resolved genes. Expression of transport-related genes was also observed to be enriched, which is 
Table 2 Anatomical enrichment of genes with high sequence coverage compared with genes having lower to no coverage

\begin{tabular}{|c|c|c|c|}
\hline \multicolumn{2}{|l|}{$\begin{array}{l}\text { Significantly enriched } \\
\text { anatomical terms } \\
\text { sequences with high ( } \geq 80 \%) \\
\text { coverage }\end{array}$} & \multicolumn{2}{|c|}{$\begin{array}{l}\text { Significantly enriched } \\
\text { anatomical terms } \\
\text { sequences with }<80 \% \\
\text { or no coverage }\end{array}$} \\
\hline Optic tectum & 0.00004 & Ovary & 0.03556 \\
\hline Epiphysis & 0.00007 & Testis & 0.04287 \\
\hline Eye & 0.00032 & Olfactory rosette & 0.04300 \\
\hline Central nervous system & 0.00038 & Cardiac ventricle & 0.04821 \\
\hline Retina & 0.00147 & & \\
\hline Liver & 0.00167 & & \\
\hline Blood & 0.00507 & & \\
\hline Neuron & 0.00548 & & \\
\hline Cranial nerve II & 0.01609 & & \\
\hline Cranial ganglion & 0.01633 & & \\
\hline Spinal cord & 0.01833 & & \\
\hline Cardiovascular system & 0.01889 & & \\
\hline Macrophage & 0.02454 & & \\
\hline Occipital lateral line neuromast & 0.02617 & & \\
\hline Myotome & 0.03472 & & \\
\hline Ventral thalamus & 0.04871 & & \\
\hline
\end{tabular}

Analysis was performed using ZEOGS, comparing enrichment of $D$. rerio genes with $\geq 80 \%$ sequence coverage (left column) compared with the list of $D$. rerio genes with $<80 \%$ or no sequence coverage (right column). Only anatomical terms that were significantly enriched (Benjamini-Hochberg adjusted $a=0.05$ ) from either list are shown along with their Benjamini-Hochberg adjusted $p$-values. consistent with a similar analysis performed after the de novo assembly of the black-faced blenny (Tripterygion delaisi) transcriptome [73].

\section{Extension of previously sequenced knifefish transcripts}

Previous cloning and characterization of $A$. leptorhynchus genes included characterization of N-methyl-D-aspartate receptors [43-45,50], HoxA paralogs [57], early growth response-1 (egr-1) [87], voltage-gated sodium and potassium channels $[42,46,49]$, Forkhead box transcription factors [88], TRP channels [47], and glutamate decarboxylases [56]. All 18 A. leptorhynchus protein sequences deposited in UniProt had at least a partial sequence in the assembly (Figure 5A). Of note, the sequence of HoxA13b was determined to be extended to completion here based on identification of a stop codon, as well as a start codon that aligned to the start of multiple homologous sequences from related species including D. rerio and the channel catfish (I. punctatus), a member of the order Siluriformes more closely related phylogenetically to A. leptorhynchus (Figure 5B).

\section{Identification of non-coding RNA (ncRNA) expression and antisense transcripts}

The importance and complexity of ncRNAs have attracted increasing attention over the last decade. Numerous classes of ncRNA are now known to be important modulators of gene expression, involved in the regulation of a wide variety of physiological and developmental processes $[89,90]$. In the CNS, ncRNAs are tightly regulated, and

\section{Structural} component of ribosome

\section{Structural molecule activity}

\begin{tabular}{|c|c|c|c|}
\hline $\begin{array}{l}\text { NADH } \\
\text { dehydrogenase } \\
\text { (ubiquinone) } \\
\text { activity }\end{array}$ & \multirow{2}{*}{$\begin{array}{l}\text { Oxidoreductase } \\
\text { activity, acting } \\
\text { on peroxide as } \\
\text { an acceptor }\end{array}$} & \multirow{2}{*}{\multicolumn{2}{|c|}{$\begin{array}{l}\text { Hydrogen ion } \\
\text { transmembrane } \\
\text { transporter } \\
\text { activity }\end{array}$}} \\
\hline $\begin{array}{l}\text { Oxidoreductase } \\
\text { activity acting on } \\
\text { NAD(P)H }\end{array}$ & & & \\
\hline $\begin{array}{l}\text { Translation } \\
\text { initiation factor } \\
\text { activity }\end{array}$ & $\begin{array}{l}\text { Unfol } \\
\text { prote } \\
\text { bindir }\end{array}$ & & $\begin{array}{l}\text { Electron } \\
\text { transport } \\
\text { activity }\end{array}$ \\
\hline $\begin{array}{l}\text { Translation factor } \\
\text { activity, nucleic } \\
\text { acid binding }\end{array}$ & $\begin{array}{l}\text { Antiox } \\
\text { activit }\end{array}$ & & Creatine kinase activity \\
\hline RNA binding & & & $\begin{array}{l}\text { Threonine-type } \\
\text { endopeptidase activity }\end{array}$ \\
\hline $\begin{array}{l}\text { Transporter } \\
\text { activity }\end{array}$ & $\begin{array}{l}\text { Oxidor } \\
\text { activity }\end{array}$ & ductase & Selenium binding \\
\hline
\end{tabular}

Figure 4 Gene Ontology treemap based on enrichment of most highly expressed transcripts. Assembly contigs that aligned to $\geq 80 \%$ of a reference $D$. rerio protein were ranked by FPKM, and the GO classification for the corresponding $D$. rerio gene were used to determine enrichment of transcripts at the top of the list using GOrilla based on the minimum hypergeometric scoring method. GOrilla analysis showed significantly enriched GO categories that were found on average in the top $9.6 \%$ of genes ( $\pm 4.8 \%$ S.D.) using minimum hypergeometric scoring. Redundant GO terms were filtered with the GO Trimming tool and then visualized with REViGO. The box size correlates to the -log10 p-value of the GO-term enrichment. Boxes with the same color are grouped by semantic similarity (SimRel, similarity $=0.7$ ). 


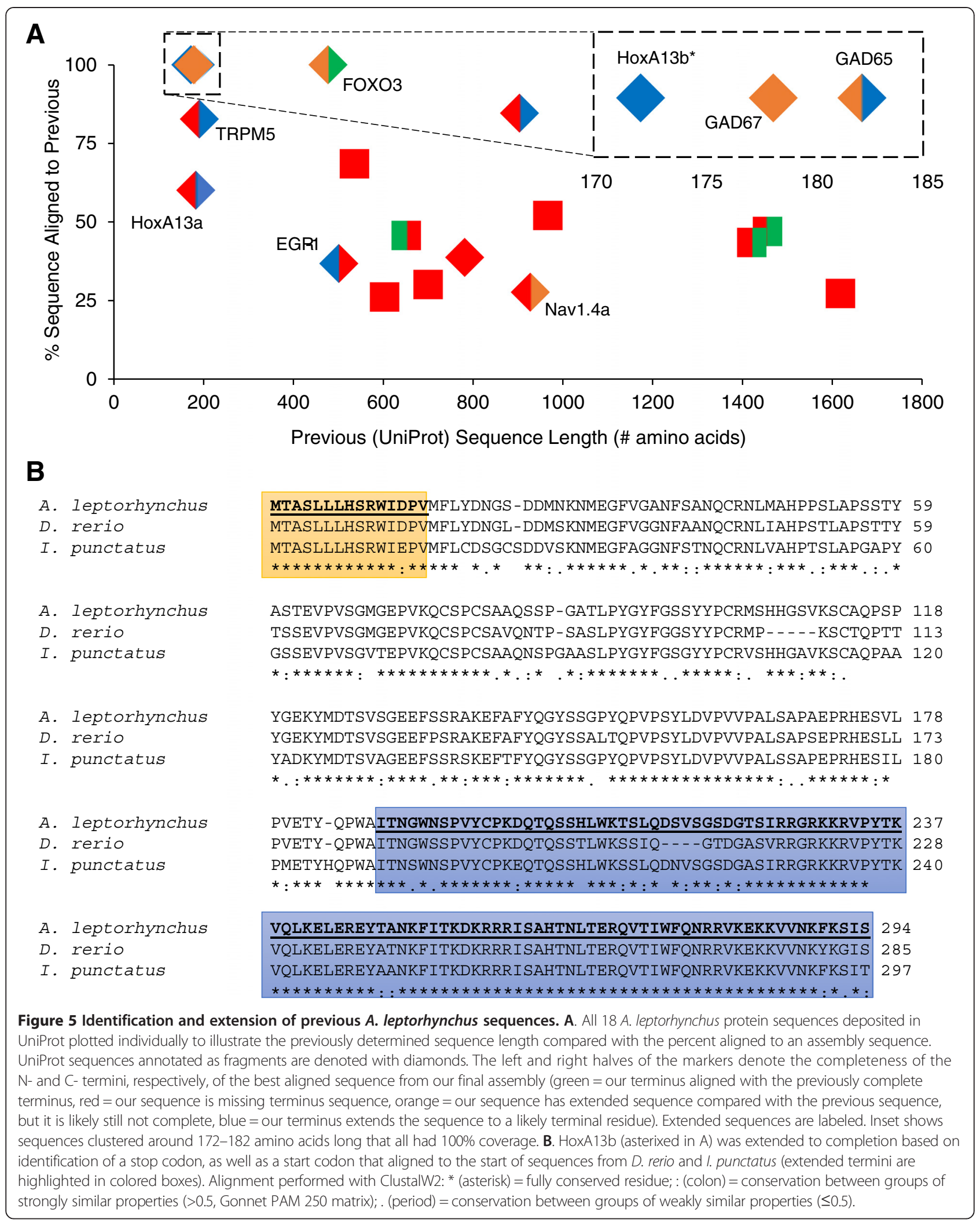


appear to play prominent roles in developmental processes such as neurogenesis and neuronal differentiation [89-91], which continue throughout adult life in A. leptorhynchus $[9,10,26,92]$.

To investigate ncRNA present in the A. leptorhynchus assembly, we compared assembly transcripts to a reference D. rerio ncRNA dataset (Danio_rerio.Zv9.75.ncrna, 8319 sequences) with BLASTn (Table 3, Additional file 5: Table S4), focusing our analysis on several major ncRNA classes including ribosomal RNA (rRNA), microRNA (miRNA), small nuclear RNA (snRNA), small nucleolar RNA (snoRNA), long non-coding RNA (lncRNA), and antisense RNA to protein-coding genes.

While our library preparation protocol was designed to limit the presence of rRNA, two contigs were found to align to $D$. rerio $5 \mathrm{~S}$ and $5.8 \mathrm{~S}$ rRNA, with two additional contigs corresponding to mitochondrial rRNA. Using an additional rRNA prediction tool, RNAmmer [94], four additional contigs were designated as 8 s rRNA (comp134303, comp138865, comp150483, and comp193485).

A total of 84 of the A. leptorhynchus assembly contigs were aligned to 81 miRNA transcripts from $D$. rerio. Out of these, 54 A. leptorhynchus assembly transcripts aligned to $\geq 80 \%$ of the corresponding $D$. rerio miRNA. Many of these alignments to miRNA sequences were included into longer assembly transcripts, which had portions

Table 3 Summary of annotated transcripts/contigs by RNA types

\begin{tabular}{|c|c|c|}
\hline Categories & $\begin{array}{l}\text { \# Transcripts (including } \\
\text { contig isoforms) }\end{array}$ & \# Contigs \\
\hline \multicolumn{3}{|l|}{ Protein sequences } \\
\hline Sense BlastX (D. rerio) & 748,404 & 40,451 \\
\hline Sense BlastX (Actinopterygii) & 759,947 & 42,459 \\
\hline \multicolumn{3}{|l|}{ rRNA } \\
\hline $\begin{array}{l}\text { rRNA (identified by } \\
\text { RNAmmer) }\end{array}$ & 59 & 4 \\
\hline rRNA (from D. rerio reference) & 2 & 2 \\
\hline $\begin{array}{l}\text { Mitochondrial rRNA } \\
\text { (from D. rerio reference) }\end{array}$ & 4 & 2 \\
\hline \multicolumn{3}{|l|}{ Other ncRNA* } \\
\hline snoRNA & 211 & 17 \\
\hline miRNA & 340 & 84 \\
\hline snRNA & 116 & 12 \\
\hline lincRNA & 419 & 54 \\
\hline SRP RNA & 1 & 1 \\
\hline Antisense & 75 & 27 \\
\hline IncRNA (Kaushik et al.) & 111 & 15 \\
\hline
\end{tabular}

Note that some transcripts were found to align to multiple categories, such as the case of transcripts containing protein-coding ORFs as well as a pri-miRNA sequence. *ncRNA was identified from D. rerio reference (ftp://ftp.ensembl.org/ pub/release-75/fasta/danio_rerio/ncrna/Danio_rerio.Zv9.75.ncrna.fa.gz) except for rRNA identified with RNAmmer and IncRNA from [93]. that aligned to $D$. rerio protein sequences, suggesting that these transcripts likely included precursor miRNAs (pri-miRNAs), transcribed in conjunction with adjacent protein coding sequences [89].

Thirteen putative snRNA were identified, including all five snRNA components of the spliceosome (U1, U2, U4, U5, and U6), as well as U11 and U12 minor spliceosomal RNA. Also detected was 7SK small nuclear RNA (rn7sk), the RNA component of the 7SK snRNP involved in the control of transcription elongation and in the regulation of pre-mRNA splicing [95]. The RNA component of the signal recognition particle (SRP), a universally conserved ribonucleoprotein that targets specific proteins to the endoplasmic reticulum in eukaryotes $[96,97]$, was also detected, with $95.1 \%$ identity across $96.6 \%$ of the corresponding $D$. rerio transcript.

Seventeen transcripts aligned to snoRNA, a family of RNA which guide chemical modification (methylation and pseudouridylation) of nascent rRNA to generate mature rRNA [90]. Amongst the snoRNA identified were 13 methylation-associated C/D-box class snoRNA and 4 pseudouridylation-associated H/ACA-box class snoRNA.

A total of 54 sequences of the A. leptorhynchus transcriptome showed significant alignment to known $D$. rerio long intergenic non-coding RNA (lincRNA), including two sequences that covered $>90 \%$ of the corresponding $D$. rerio lincRNA. While sequence coverage was generally low, alignments to $>1000$ nucleotides with close to $80 \%$ identity were found.

To further investigate the presence and conservation of lncRNA expressed in adult CNS tissues of A. leptorhynchus, the assembly was searched against an additional set of lncRNAs expressed in adult $D$. rerio, including many with specific expression in the brain. LncRNAs have been shown to be expressed with high tissue specificity, in particular in the brain [98], where they have been associated with the control of neuronal diversification and specification [91]. Kaushik et al. reported a set of 419 novel lncRNAs, including 47 specifically expressed in adult $D$. rerio brain when compared with heart, liver, muscle, and blood [93]. Amongst these, we found evidence for at least one conserved lncRNA expressed exclusively in the brain (lncBr_002), as well as 10 additional lncRNAs found in adult $D$. rerio brain and other tissues examined, and finally 4 lncRNAs that were not observed in the brain previously, but were found in blood. It is possible that these transcripts could be novel, functional IncRNA. However, further investigation will be required to exclude the possibility of contamination from remaining blood vessels in the isolated brain tissue.

Antisense transcription contributes to the complexity of expression dynamics, and while antisense transcripts can play roles in regulating translation and splicing, separating functional antisense transcripts from transcriptional noise 
remains a challenge. Out of the 682 antisense sequences in the available $D$. rerio ncRNA reference set, only 25 had significant alignments (e-value $<10^{-10}$ ) to transcripts from 27 contigs in the $A$. leptorhynchus assembly, with significant alignments ranging from $46 \mathrm{bp}$ to $930 \mathrm{bp}$. Expression of thousands of antisense transcripts was found to be conserved across humans, mice, and rats, although to a lesser degree than protein-coding genes [99]. The relatively low coverage of antisense transcripts from $D$. rerio may be due to lack of sufficient sequencing depth or to the restriction of our analysis to RNA expressed in adult CNS tissue.

\section{Detection of protein-coding ORFs and putative protein-coding gene duplications}

To determine the overall protein-coding potential of transcripts in the A. leptorhynchus assembly, regardless of their alignment to known Actinopterygii protein sequences, protein-coding ORFs were predicted from the assembly using TransDecoder [68], both with and without biasing "best" ORF calling towards ORFs with a recognizable domain in the Pfam protein families database [100]. When limiting the set of ORFs from each search to only those comprising at least 100 amino acids, the resulting distributions of ORF lengths were similar overall, regardless of whether or not Pfam domains were used for guiding ORF selection (Additional file 6: Figure S2A-B). Similarly, filtering for transcripts with FPKM $\geq 1$ had little effect on ORF size distribution without Pfam (Additional file 6: Figure S2C-D), suggesting that resolution of the distribution of ORF lengths of 100 amino acids or greater was independent of expression levels. BLAST aligning ORFs with or without guidance from Pfam against the $D$. rerio reference sequence demonstrated that the Pfam option did slightly increase identification of ORFs with conserved protein coding sequences (Additional file 6: Figure S2E-F). Out of the approximately 202,000 A. leptorhynchus transcripts with $\mathrm{FPKM} \geq 1,87,945$ transcripts with ORFs comprising at least 100 amino acids (as found with Pfam) aligned to D. rerio protein sequences. Transcripts with FPKM values $\geq 1$ covered a total of 21,638 unique $D$. rerio proteins, or over $80 \%$ of the identifiable sequences (Additional file 6: Figure S2G). When transcripts with FPKM values $<1$ were included, this coverage increased to 26,588 unique $D$. rerio sequences, indicating that even transcripts expressed at low levels could still provide recognizable sequences. An additional 6,090 transcripts with FPKM $\geq 1$ contained ORFs of over 100 amino acids that did not align to a $D$. rerio protein in our reference sequence set. However, after BLAST aligning these ORFs against the entire NCBI non-redundant (nr) protein sequence database, 3,505 additional sequences had significant alignments 3,273 of these alignments were to sequences from Teleostei species (Additional file 6: Figure $\mathrm{S} 2 \mathrm{H}$ ) showing a similar trend to the results from the nt sequence set, including 2,079 A. mexicanus sequences and $425 \mathrm{D}$. rerio sequences absent from the UniProt reference set.

In order to identify potential A. leptorhynchus duplicated genes (relative to $D$. rerio), we examined instances where multiple distinct assembly contigs were aligned to the same $D$. rerio protein. Only sufficiently large contigs, with transcripts that could be aligned to at least $80 \%$ of a given $D$. rerio protein sequence, were selected. Using this threshold, we observed a 1:1 correspondence between assembly contigs and unique $D$. rerio proteins for 7,692 sequences. There were 491 instances of two contigs aligning to the same $D$. rerio protein, and 41 instances of three or more contigs aligning to the same D. rerio protein (Figure 6A, Additional file 7: Table S5).

One example of multiple distinct $A$. leptorhynchus assembly contigs aligning to the same $D$. rerio protein is ubiquitin-conjugating enzyme E2 D2 (UBC4/5 homolog, yeast) (Q6PBX6_DANRE, Figure 6B), in which case four A. leptorhynchus assembly contigs aligned to one known $D$. rerio protein. In this case, the four sequences are generally well conserved, including the cysteine active site. A more divergent example is the uncharacterized $D$. rerio protein A2BHK0, where four A. leptorhynchus assembly contigs had substantially different alignments at the termini (Additional file 8: Figure S3). Several examples of multiple contigs aligning to the same $D$. rerio protein sequence included proteins with multiple coding genes such as calmodulin, a $\mathrm{Ca}^{2+}$ binding protein involved in mediating a variety of cellular responses to variations in $\mathrm{Ca}^{2+}$ levels [101], which is coded for in six separate loci of the $D$. rerio genome, and seven assembly contigs of the $A$. leptorhynchus CNS (Table 4).

To exclude the possibility that contigs we assigned as putative duplicated genes (relative to $D$. rerio) are the result of artifactual contig splitting by Trinity, we compared at the nucleotide level the ORFs of the 491 contigs assigned as having a single duplication (i.e. two distinct contigs with full or near-full length ORFs that align to a single $D$. rerio protein sequence). Aligning the ORFs of these pairs of contigs, we observed substantially different sequences at the nucleotide level (sequence identity $=61 \pm 8 \%, \mu \pm \sigma$ ), with sequence identity ranging from a maximum of $87 \%$ and minimum of $34 \%$. Such a high dissimilarity between two ORF sequences suggests these contigs derive from different genomic loci. That both sequences produce significant alignments covering $>80 \%$ of the same target protein sequence (from D. rerio) suggests that these contigs are both: 1) full or near-full length; and 2) encode related protein products.

Validation of putative protein coding regions via shotgun proteomics analysis of the $A$. leptorhynchus CNS

To confirm translation of assembly ORFs, including alternative isoforms of particular contigs, and to demonstrate the usefulness of the assembly for increasing peptide 


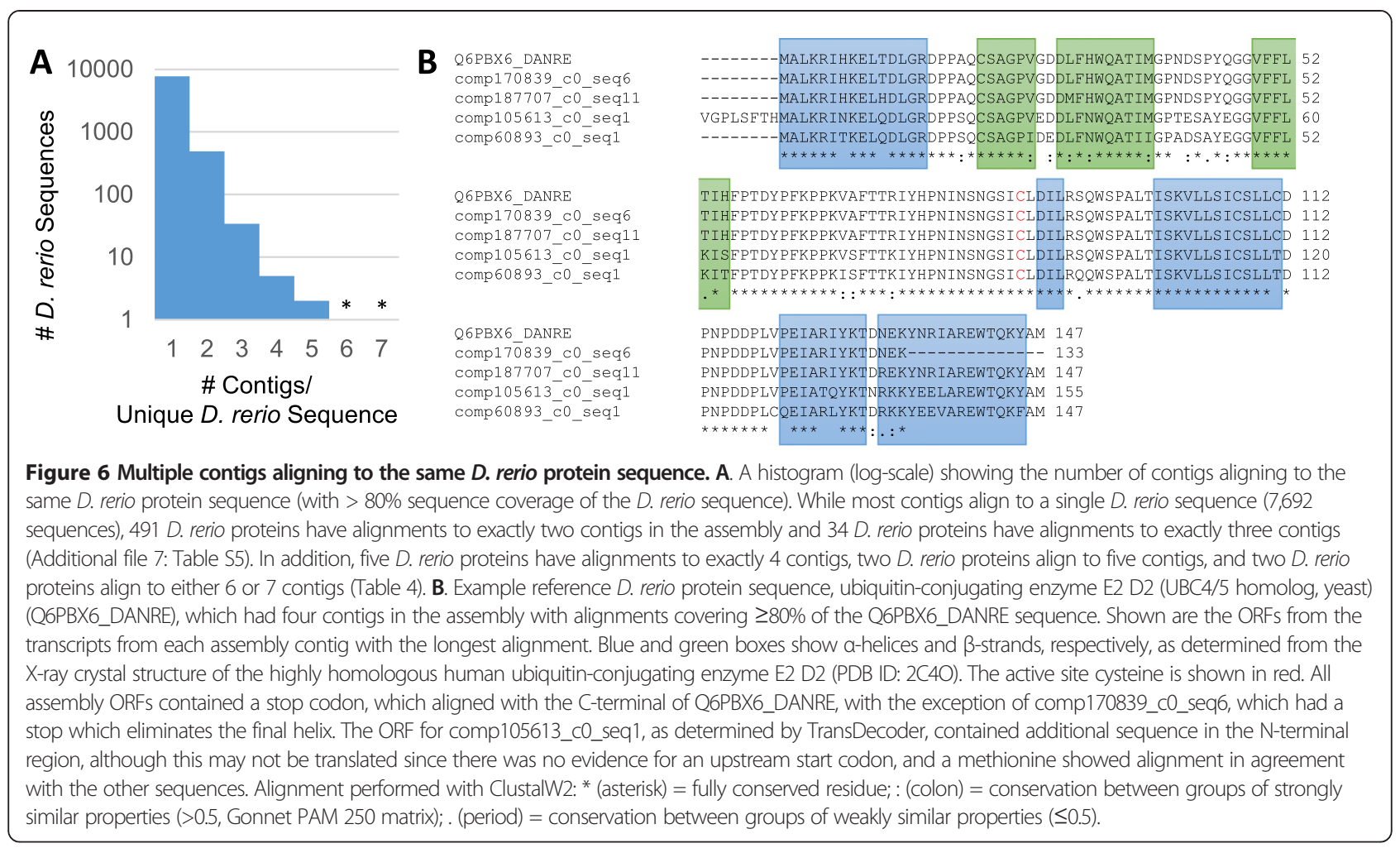

assignments during tandem mass spectrometry analysis, we characterized protein extracts harvested from A. leptorhynchus brain and spinal cord by shotgun proteomics. Two sample preparation methods, the popular in-gel digest [102], and the recently introduced enhanced filter-aided sample preparation method [103] (eFASP, which tends to enrich membrane-bound proteins), were used. Tissue samples from both brain and spinal cord were used in order to broaden and enhance our coverage of the CNS proteome. Base peak chromatograms across a 4-hr gradient (5-40\% acetonitrile) revealed a complex mixture of digest peptides (Figure 7A).

To analyze tandem mass spectrometry data, we used Mascot, which utilizes probability-based scoring in order to match tandem mass spectra to protease digest peptides predicted from a given sequence database [104]. In Mascot, limiting the reference database size, as occurs when searching only the appropriate genus and species, increases probability-based scoring and leads to a greater percentage of statistically significant identifications. Alternatively, including more sequences, for example incomplete fragments, such as those found in our assembly, or proteins from other organisms that may not have been covered in the present assembly, could increase the total number of protein IDs, but may negatively impact scoring based on adjustments due to database size. We therefore considered several approaches when preparing our assembly as a sequence database for Mascot, including using only long
ORFs (at least 100 amino acids), only ORFs from transcripts with FPKM values $\geq 1$, or all ORFs regardless of size, and compared these results to results obtained using available sequences of $D$. rerio, as well as other Actinopterygii sequences, from NCBI.

Notably, any ORF set derived from the A. leptorhynchus assembly provided the most assignments at both the peptide and protein level when compared with the results from other existing databases. The results were compared using several different false discovery rates (FDR) (Figure 7B-D). As many as 2,813 proteins were identified (from 58,106 peptide assignments) with the conservative 1\% FDR from the database containing all assembly ORFs (Additional file 9: Table S6). Within Mascot-assigned "protein families", similar protein sequences identified from a given database are grouped together. These groups can include paralogous sequences (both known and unique) and alternatively spliced variants. When comparing the Mascot protein families with annotations from BLAST results, there was good agreement between the Mascot assigned protein families and known paralogues identified from alignment with $D$. rerio. For example, the first protein family assigned by Mascot included twelve ORFs from the $A$. leptorhynchus assembly that corresponded, after BLAST searching, to multiple isoforms of alpha tubulin, including tubala, tuba1c, tuba8l, tuba8l2, tuba8l3, and tuba8l4. Likewise, the second protein family assigned by Mascot included 15 ORFs from the A. leptorhynchus assembly that 
Table $4 D$. rerio proteins with $\geq 4$ contigs aligning to $\geq 80 \%$ of the $D$. rerio sequence

\begin{tabular}{|c|c|c|c|}
\hline D. rerio reference protein (UniProt ID) & Protein name & \# Contigs in assembly & \# of D.rerio genes \\
\hline CALM_DANRE & Calmodulin (CaM) & 7 & 6 \\
\hline E7F3G4_DANRE & Uncharacterized protein & 6 & 1 \\
\hline H33_DANRE & Histone H3.3 & 5 & 4 \\
\hline E7FDA5_DANRE & Uncharacterized protein & 5 & 1 \\
\hline A2BHKO_DANRE & Uncharacterized protein & 4 & 1 \\
\hline F1R8F5_DANRE & Uncharacterized protein (fragment) & 4 & 1 \\
\hline F8W544_DANRE & Phosphatidylinositol transfer protein, alpha b & 4 & 1 \\
\hline Q6P2T9_DANRE & Cd63 antigen & 4 & 1 \\
\hline Q6PBX6_DANRE & Ubiquitin-conjugating enzyme E2D 2 (UBC4/5 homolog, yeast) & 4 & 1 \\
\hline
\end{tabular}

Multiple sequence alignment of assembly sequences to phosphatidylinositol transfer protein (F8W544_DANRE) is shown in Figure 6B. Similarly, a multiple sequence alignment of assembly sequences compared to uncharacterized $D$. rerio protein (A2BHK0) is shown in Additional file 8: Figure S3.

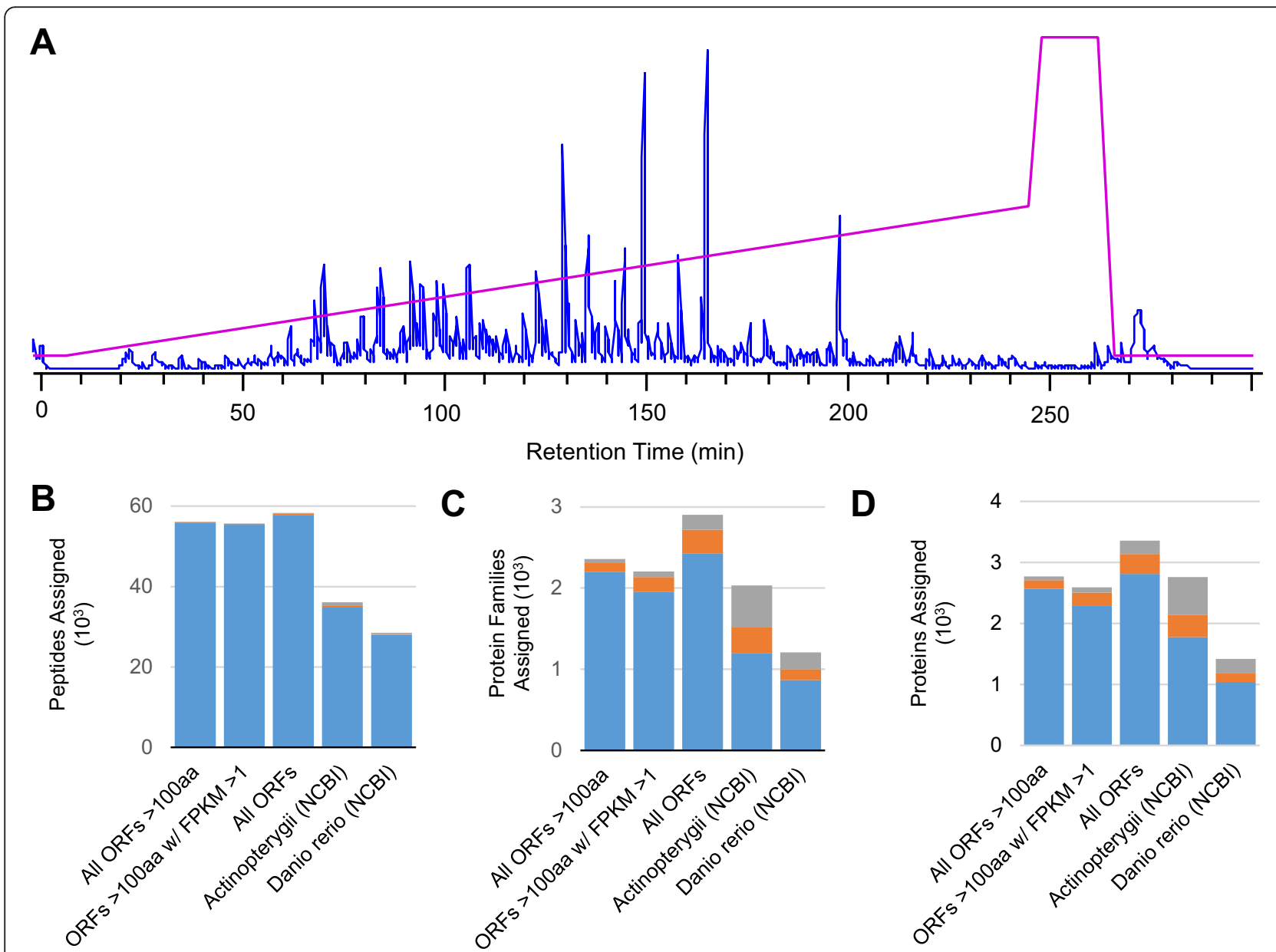

Figure 7 Utility and optimization of de novo assembly for LC-MS/MS shotgun proteomics database searching. A. Representative base peak chromatogram (blue) of trypsin digested A. leptorhynchus central nervous tissue protein extract across a 4 hour gradient (magenta). B-D. Enhancement of IDs by database by peptide ID, Mascot-assigned protein families, and individual protein at multiple false discovery rate thresholds $(1 \%=$ blue bar, $2 \%=$ orange bar, $5 \%=$ grey bar). 
all aligned to beta tubulin isoforms. The 2,813 proteins identified (FDR $<1 \%$ ) from the database containing all assembly ORFs were grouped by Mascot into 2,424 protein families.

Limiting the number of sequences in the database (by either filtering by FPKM or by ORF length) did not benefit the probabilistic assignment of tandem mass spectra, and including more sequences, such as partial and lowexpression sequences, was not observed to be a limiting factor. Including shorter and less abundant transcripts from the $A$. leptorhynchus assembly helped in peptide assignment. In the present study, short ORFs identified through proteomics often represented terminal fragments of transcripts that were not fully assembled (these ORFs lacked 5' and/or 3' ends).

After matching the final list of identified ORFs from the A. leptorhynchus proteomics dataset with BLAST results from $D$. rerio, we examined the coverage of various $\mathrm{GO}$ categories. Consistent with the transcriptome assembly described above, the ribosome was the best-covered cellular component by proteomics, with peptides being assigned to nearly $40 \%$ of the protein constituents of the ribosome (Figure 8A). In terms of molecular function, we observed the highest coverage of structural molecules, as well as antioxidant proteins, reflecting mainly the prominence of mitochondrial antioxidant enzymes (Figure 8B).

A powerful benefit of combined transcriptomics and proteomics is the ability to confirm translation of alternatively spliced transcripts through the detection of splice junction peptides [105]. For example, within the spectrin family, which contained nine ORFs that were identified by proteomics, including spta2, sptb, sptbn1, sptbn2, there were two assembly ORFs derived from different transcript isoforms within the same contig, both aligned to D. rerio spta2. These two ORFs, with lengths of 1760 and 1780 amino acids, and both assigned as complete sequences based on TransDecoder, were identical except for the addition sequence TAVTKETCSVSVRMKQVEEL, present after amino acid Q352. Comparison of MS/MS sequence coverage confirmed the identification of unique splice junction peptides from each sequence (Figure 8C-E). Overall, there were 209 contigs identified in the proteomics results that had 2 or more isoforms with non-redundant ORFs identified (with two contigs each having 5 transcripts identified), although manual inspection of MS/MS for putative splice junction peptides is necessary to rule out false positives.

\section{Conclusions}

The present study represents the first major collection of transcriptomics data for a species of the order Gymnotiformes, weakly electric fish from South and Central America with great relevance for neurobiological research. Previously, only nineteen A. leptorhynchus mRNA sequences were publically available. With our de novo assembly of the adult A. leptorhynchus CNS transcriptome, broad coverage of protein-coding sequences was achieved, with as many as 11,847 contigs presenting full or near-full length ORFs. Our study provides the first survey of a broad variety of ncRNA in A. leptorhynchus, including miRNA, snRNA, snoRNA, and other ncRNA sequences. Shotgun proteomics confirmed translation of ORFs from over 2,000 transcripts, including alternative splice variants. Our de novo transcriptome-to-proteome analysis contributes to the growing trend of incorporating these two techniques for enhancing shotgun proteomics identifications while confirming ORF assignment from transcriptome assembly experiments.

A. leptorhynchus is an important model organism in particular for the study of fundamental neurobiological aspects, such as adult neurogenesis, neuronal regeneration, and the neural basis of behavior. The availability of a targeted CNS reference transcriptome will provide novel molecular tools to explore the underlying cellular mechanisms of such phenomena. In addition, the sequence information provided here can be employed to study phylogenetic relationships and various aspects of CNS evolution in vertebrates. Future studies, using libraries from different tissues and developmental stages, will further improve the quality and applicability of the A. leptorhynchus assembly.

\section{Methods}

\section{Animals}

Brown ghost knifefish (Apteronotus leptorhynchus) were supplied by tropical fish importers and maintained in the laboratory as described previously [17]. A total of 10 individuals were used for sequencing, and 26 fish were used for the proteomics experiments. Both males and females were included, and all fish were adults in their second or third year of life. All animal experiments were approved by the Institutional Animal Care and Use Committee of Northeastern University. All efforts were made to reduce the number of animals used and to minimize animal suffering.

\section{RNA-Seq library preparation and paired-end sequencing}

Total RNA was extracted from brain samples collected individually from 3 adult females, as well as pooled spinal cord samples collected from 7 male and female individuals, using an Aurum Total RNA Fatty and Fibrous Tissue Kit (Bio-Rad, Hercules, CA). RNA quality was determined by calculating the RNA Integrity Number (RIN) after performing a Eukaryote Total RNA Pico assay on a Bioanalyzer 2100 (Agilent, Santa Clara, CA). A strand-specific cDNA library for Illumina-based sequencing-by-synthesis was created using the TruSeq Stranded mRNA Sample Prep kit (Illumina, San Diego, CA). Briefly, polyadenylated mRNA was purified using poly-dT oligo-attached magnetic beads. Following purification, the mRNA was fragmented 


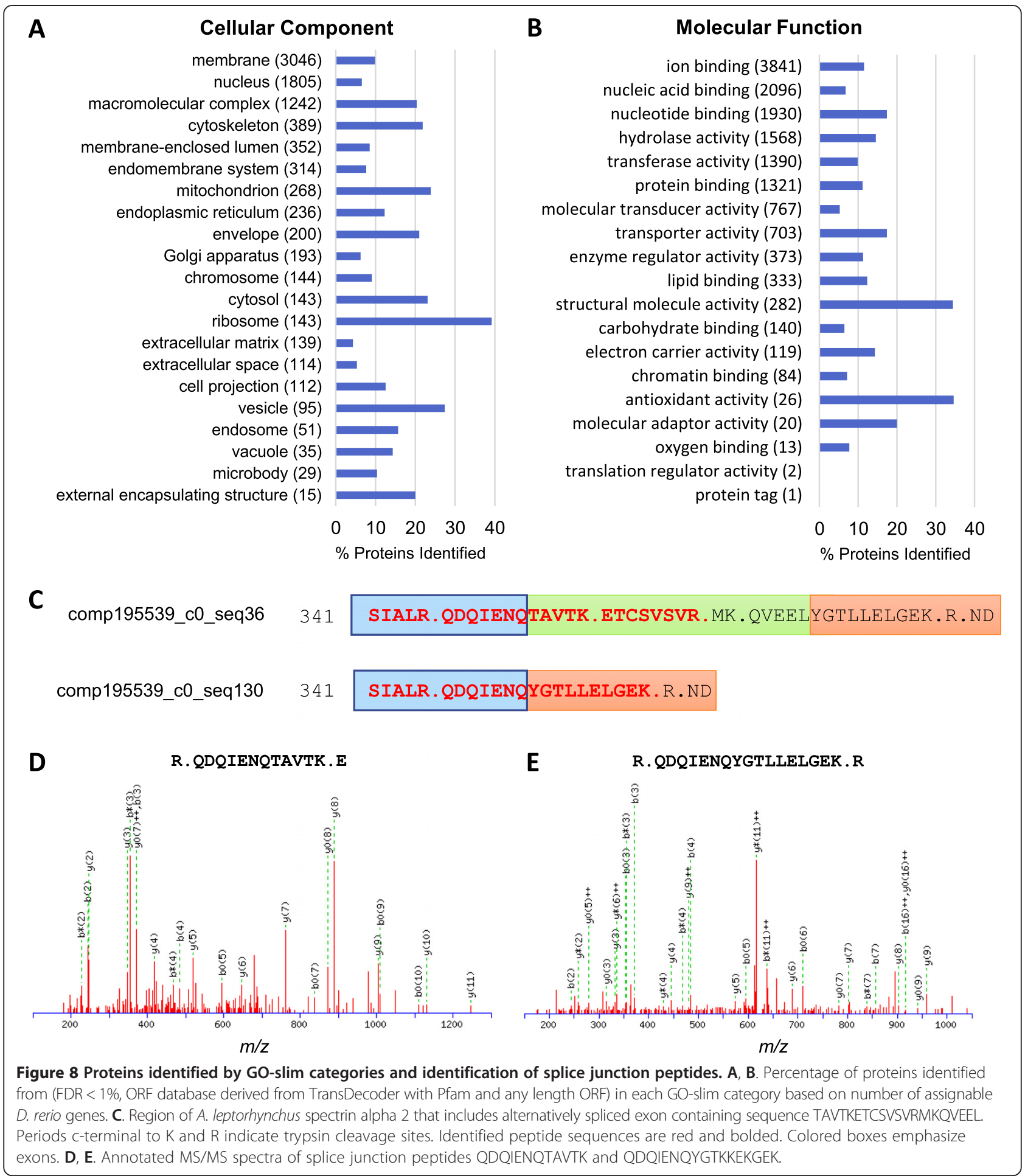

into small pieces using divalent cations under elevated temperature. The cleaved RNA fragments were reverse transcribed into first strand cDNA using reverse transcriptase and random primers. This was followed by second strand cDNA synthesis using DNA Polymerase I and RNase $\mathrm{H}$ in the presence of dUTP, which is incorporated into the second strand to prevent its amplification during subsequent PCR [106]. 3' ends of double-stranded cDNA fragments were adenylated to permit ligation of barcoded adapters that allow for sorting of sequenced fragments that had been pooled prior to sequencing. The products were then purified and enriched with PCR to create the 
final strand-specific cDNA library. Concentration and quality of strand-specific cDNA libraries was assessed by NanoDrop (Thermo Scientific, Waltham, MA) and High Sensitivity DNA assay on a Bioanalyzer 2100, respectively. Paired-end sequencing $(2 \times 150$ cycles $)$ of pooled, strand-specific cDNA libraries derived from mRNA-enriched extracts was performed on MiSeq and HiSeq 2500 instruments (Illumina). After sequencing, reads were mapped to their respective samples based on ligated barcoded adapter sequences with CASAVA 1.8.2 (Illumina). Read quality was examined with FastQC and FastqScreen, which confirmed that read fidelity was maintained during sequencing and contamination from other organisms was negligible.

\section{De novo transcriptome assembly and transcript annotation}

Reads were trimmed with Trimmomatic [107]. The "soft trimming" read set included reads trimmed to eliminate adapter sequences, leading and tailing bases with quality score less than 3 (including uncalled bases), and reads shorter than $35 \mathrm{bp}$ after trimming. The "hard trimming" read set included reads trimmed with the "soft trimming" parameters as well as a 4-base wide sliding window, cutting when the average quality per base dropped below 15 . Unpaired reads remaining after trimming were also removed in either case.

The trimmed read sets were then assembled using Trinity [68,76] (November 11, 2013 release) with default settings (which include minimum transcript length of $200 \mathrm{bp}$ ) for strand-specific, paired-end read sets. To reduce assembly time, trimmed reads were normalized prior to assembly using the in silico normalization script included with Trinity with default settings for strand-specific sequences. To evaluate the necessity of extensive alternative transcript reconstruction, additional Trinity assemblies were also performed using the extended lock feature of Butterfly. CuffFly and PasaFly were also examined as alternative transcript reconstruction methods.

To compare quality of Trinity assemblies based on trimming and transcript reconstruction strategies, sequences were blasted (BLASTx, version 2.2.28, E-value cut-off $=10^{-5}$ ) against a locally installed BLAST database containing the UniProtKB $D$. rerio complete proteome sequence set (41,102 sequences, retrieved April 2nd, 2014). The best assembly was further examined with BLASTx against two sequence sets (also retrieved April 2nd, 2014 from UniProtKB), including: an A. leptorhynchus protein set (18 sequences) and an Actinopterygii complete proteome set $(211,131$ sequences). The NCBI nt sequence set (retrieved August 17th, 2014) was used to BLASTn search the assembly. To identify ncRNA sequences, transcripts were blasted (BLASTn) against the Ensembl [108] D. rerio ncRNA database [109] (ftp:// ftp.ensembl.org/pub/release-75/fasta/danio_rerio/ncrna/
Danio_rerio.Zv9.75.ncrna.fa.gz), and an additional set of 417 lncRNA found in adult $D$. rerio [93]. RNAmmer 1.2 [94] was used to predict rRNA sequences in transcript assembly using scripts within Trinotate and HMMER 2.3.2 [110]. Vector and primer contamination was identified by VecScreen (http://www.ncbi.nlm.nih.gov/tools/vecscreen/) and contaminants were removed prior to depositing with NCBI. FPKM (fragments per kilobase of exon per million fragments mapped) of transcripts was calculated by estimating transcript abundance using RSEM (RNA-Seq by Expectation Maximization) [111], followed by TMM (trimmed-mean of $M$-values) normalization within Trinity.

\section{Gene ontology enrichment and KEGG pathway analysis} The WEB-based GEne SeT AnaLysis Toolkit (WebGestalt) $[112,113]$ was used to map transcripts from blastX analysis of the $D$. rerio reference proteome to GO-slim categories and KEGG pathways. For this analysis, the corresponding $D$. rerio gene name for BLASTx-matched sequences with greater than $80 \%$ subject sequence coverage were used. For GO enrichment analysis, the same gene list was ranked by FPKM. In the case of multiple transcripts aligned to the same $D$. rerio protein, the FPKM of the highest expressed transcript corresponding to a given $D$. rerio protein was used to determine its rank in the list. The ranked list was analyzed with GOrilla [86,114] (Gene Ontology enRIchment anaLysis and visuaLizAtion tool). This process was performed similarly for proteomics results, using the $D$. rerio gene names from the BLASTp searches of the corresponding putative ORFs from TransDecoder (described below). Significant GO terms (Benjamini-Hochberg adjusted $p$-value $<0.001$ ) were hard trimmed for redundancy using the GO Trimming tool [115]. REVIGO [116] was then used to analyze the trimmed GO IDs and corresponding $p$-values to further combine GO categories $(0.5$ similarity) and visualize the results with a treemap scaled by $-\log _{10} p$-values. For anatomical expression enrichment analysis, gene lists were analyzed with ZEOGS [85] using gene anatomical annotation from ZFIN and the adult stage filter (Benjamini-Hochberg adjusted hypergeometric $p$-value $<0.05)$.

\section{Protein extraction and sample preparation for proteomics}

Brain and spinal cord tissues were isolated rapidly on ice and stored at $-80^{\circ} \mathrm{C}$. To increase overall coverage of identified proteins, samples were prepared using both in-gel digestion and eFASP. In-gel digestion was performed as previously described [117]. Tissue samples were homogenized for $3 \mathrm{~min}$ on ice in lysis buffer containing $50 \mathrm{mM}$ Tris, $120 \mathrm{mM} \mathrm{NaCl}, 1 \mathrm{mM}$ EDTA, 1\% Triton X-100, 0.1\% SDS, $10 \%$ glycerol (all from Fisher Scientific), $\mathrm{pH}$ 7.4, using a hand-held pestle homogenizer. The homogenate was placed in a rotating mixer for $40 \mathrm{~min}$ at $4^{\circ} \mathrm{C}$, centrifuged for $10 \mathrm{~min}$ at $16,000 \times \mathrm{g}$, and the supernatant was 
collected and stored at $-80^{\circ} \mathrm{C}$. Protein concentration was determined using a BCA assay (Pierce). Samples were loaded onto $12 \%$ acrylamide gels (Bio-Rad) at $50 \mu \mathrm{g}$ total protein per lane, and run at $120 \mathrm{~V}$ until the protein front was well focused at the beginning of the resolving gel, before band separation. The gels were transferred into fixative solution containing 10\% acetic acid, 50\% methanol (all from Fisher Scientific), and 40\% water for $30 \mathrm{~min}$, stained for a few seconds with Ponceau S (Boston Bioproducts, Inc.), then destained in fixative solution for 2-3 hours, until the protein band was clearly visible and the background minimal. The protein bands were excised, fragmented into $1-\mathrm{mm}^{3}$-pieces, and stored in $1 \%$ acetic acid in water at $4^{\circ} \mathrm{C}$ overnight. The gel pieces were dried with $500 \mu \mathrm{l}$ acetonitrile for $10 \mathrm{~min}$, reduced with $10 \mathrm{mM}$ DTT in $100 \mathrm{mM}$ ammonium bicarbonate for $30 \mathrm{~min}$ at $56^{\circ} \mathrm{C}$, dried with acetonitrile, alkylated with $55 \mathrm{mM}$ iodoacetamide in $100 \mathrm{mM}$ ammonium bicarbonate for $20 \mathrm{~min}$ at room temperature, and dried again with acetonitrile. The dried gel pieces were saturated with a solution of $13 \mathrm{ng} / \mu \mathrm{l}$ trypsin (Princeton Separations, Inc.) in $10 \mathrm{mM}$ ammonium bicarbonate containing $10 \%$ acetonitrile, and incubated overnight in a thermo-mixer at $37^{\circ} \mathrm{C}$ and $400 \mathrm{rpm}$. Digests were extracted by adding a 1:2 solution of $5 \%$ formic acid in water and acetonitrile, followed by incubation at $37^{\circ} \mathrm{C}$ and $400 \mathrm{rpm}$ for $15 \mathrm{~min}$. Supernatant aliquots were collected and dried using a vacuum centrifuge.

eFASP was performed as previously described, with minor modifications [103]. Tissue samples were fragmented and incubated in a thermo-mixer for $10 \mathrm{~min}$ at $95^{\circ} \mathrm{C}$ and $600 \mathrm{rpm}$, in lysis buffer containing 4\% SDS, $0.2 \%$ sodium deoxycholate, $50 \mathrm{mM}$ Tris(2-carboxyethyl)phosphine hydrochloride, $100 \mathrm{mM}$ ammonium bicarbonate, $\mathrm{pH}$ 8. The sample was further homogenized on ice using a sonicator, centrifuged at $14,000 \times \mathrm{g}$, sonicated and pelleted again, and the supernatant was collected and stored at $-80^{\circ} \mathrm{C}$. For sample processing, $25 \mu \mathrm{l}$ of tissue lysate were mixed with $200 \mu \mathrm{l}$ exchange buffer, containing $8 \mathrm{M}$ urea, $0.2 \%$ sodium deoxycholate, $100 \mathrm{mM}$ ammonium bicarbonate, $\mathrm{pH} 8$, and dispensed onto a Vivaspin 500 filter unit, $30 \mathrm{kDa}$ MWCO (GE Healthcare), and centrifuged at $15,000 \times \mathrm{g}$. After two further washes with exchange buffer, the sample was alkylated by incubating for 1 hour at $37^{\circ} \mathrm{C}$ and $300 \mathrm{rpm}$ with $100 \mu \mathrm{l}$ buffer containing $8 \mathrm{M}$ urea and $50 \mathrm{mM}$ iodoacetamide in $100 \mathrm{mM}$ ammonium bicarbonate, $\mathrm{pH}$ 8. After centrifugation for $10 \mathrm{~min}$ at $15,000 \times \mathrm{g}$, and two further washes with $200 \mu \mathrm{l}$ exchange buffer each, the sample was washed three times with digestion buffer containing $0.2 \%$ sodium deoxycholate in $50 \mathrm{mM}$ ammonium bicarbonate, $\mathrm{pH} 8$. Trypsin was added in $100 \mu \mathrm{l}$ digestion buffer at a ratio of 1:50 with the total protein in the sample, and the unit was incubated overnight at $37^{\circ} \mathrm{C}$ and $300 \mathrm{rpm}$. After centrifugation for $10 \mathrm{~min}$ at $15,000 \times \mathrm{g}$, the unit was washed twice with $50 \mu \mathrm{l}$ of $50 \mathrm{mM}$ ammonium bicarbonate, and all filtrate was collected. To remove residual detergent, $1 \mathrm{ml}$ of ethyl acetate was added to the sample, sonicated for 10 seconds and centrifuged for $10 \mathrm{~min}$ at $16,000 \times \mathrm{g}$, and the upper organic layer removed. This process was repeated three times, then the aqueous samples were placed in a thermomixer at $60^{\circ} \mathrm{C}$ for $5 \mathrm{~min}$, to remove residual ethyl acetate. The samples were then dried in a vacuum centrifuge and resuspended in 50\% methanol several times to remove residual salts.

\section{LC-MS/MS and data analysis for protein identification}

Protein extract digests were analyzed on an impact HD QqTime-Of-Flight (Qq-TOF, Bruker Corporation, Billerica, MA) with a CaptiveSpray ion source (Bruker-Michrom, California, USA). The mass spectrometer was coupled to an Ultimate 3000 nano-LC system (Dionex, California, USA) fitted with an in-house packed C18 column (500 mm x $100 \mu \mathrm{m}, 2.5 \mu \mathrm{m}$ beads, XSelect, Waters Corp., Milford, MA). Solvent A was $0.1 \%$ formic acid in water, and solvent $\mathrm{B}$ was $0.1 \%$ formic acid in acetonitrile. The following gradient conditions were used: $\mathrm{t}=0-5 \mathrm{~min}, 5 \%$ solvent $\mathrm{B} ; \mathrm{t}=245 \mathrm{~min}, 40 \%$ solvent $\mathrm{B} ; \mathrm{t}=248-262 \mathrm{~min}$, $80 \%$ solvent $\mathrm{B} ; \mathrm{t}=265 \mathrm{~min}, 5 \%$ solvent $\mathrm{B}$. The flow rate was $1 \mu \mathrm{L} / \mathrm{min}$. Tandem mass spectra were acquired at an intensity-dependent rate of $4-20 \mathrm{~Hz}$ between precursor scans.

LC-MS/MS spectra were initially analyzed in DataAnalysis 4.2 (Bruker). Compounds were detected based on an AutoMSn intensity threshold of $10^{4}$ and exported to a Mascot generic file (MGF) using the Protein Analysis function. The MGFs from individual runs were imported into ProteinScape 3.1 (Bruker), combined, and proteins were identified from LC-MS/MS runs by searching the MS/ MS spectra using a local Mascot (Matrix Science Inc, Boston, MA) server. All Mascot searches were performed using trypsin as the enzyme, up to two missed cleavages allowed, carbamidomethyl cysteine as a fixed modification, oxidized methionine and deamidated asparagine/glutamine as variable modifications, 10 -ppm tolerance on the precursor and 0.5-amu tolerance on the product ions, and charge states of $+1,+2$, and +3 . Identifications were evaluated using MudPIT scoring, with a minimum peptide score of 20. A decoy database search was performed to allow correction of protein identifications by a FDR threshold of $1 \%$, $2 \%$, and $5 \%$ probability, as described in Results and discussion. For Mascot searches based on public data, the NCBI database searches were limited to either $D$. rerio sequences or the Actinopterygii taxon. To construct databases built around our A. leptorhynchus assembly, "mostly likely" longest-ORF peptides candidates were generated from the assembly using TransDecoder (http://transdecoder.sourceforge.net/), both with and without ORF calling being biased towards ORFs with a recognizable domain in the Pfam 
protein families database [118] determined by HMMER 3.1 $[119,120]$. Redundant ORFs within sets were removed prior to compiling the ORF sets as Mascot databases.

\section{Availability of supporting data}

This Transcriptome Shotgun Assembly project (BioProject ID PRJNA259518) has been deposited at DDBJ/EMBL/ GenBank under the accession GBKR00000000. The version described in this paper is the first version, GBKR01000000. The mass spectrometry proteomics data have been deposited at the ProteomeXchange Consortium [121] via the PRIDE partner repository [122] with the dataset identifier PXD001285 and DOI 10.6019/PXD001285.

\section{Additional files}

Additional file 1: Figure S1. Optimization of pre-assembly trimming and transcript reconstruction and the effect of FPKM filtering on the distribution of transcripts per contig and distribution of transcript length in the assembly. A. Relative to the total number of protein sequences in the $D$. rerio reference proteome set $(41,112$ sequences, black bar), similar coverage was achieved regardless of trimming strategy, although the "soft" trimming strategy provided a minor advantage over "hard" trimming, recovering $2.44 \%$ more transcripts with at least $80 \%$ sequence coverage (12,446 sequences, including antisense alignments, for soft trimming compared with 12,149 sequences for hard trimming). B. While the alternative transcript reconstruction methods reduced the overall number of transcripts, they produced similar number of overall contigs. C. The default (Butterfly) transcript reconstruction provided enhanced sensitivity, with $7.98 \%$ more sequences aligned than the next best reconstruction method $(12,446$ sequences covered with Butterfly compared with 11,526 with PasaFly). D. From the raw assembly, the number of transcripts per contig followed a power law, with many contigs having few transcripts and a few contigs having many (100-1000) transcripts. E. After filtering for transcripts with FPKM $\geq 1$, the number of transcripts per contig was reduced to following a log distribution, where even though many contigs still had multiple transcripts, the number of transcripts was on the order of 10s. F. For the overall assembly, the size distribution of transcripts peaked between 1,000 and 10,000 nucleotides. G. When considering only the longest transcript per contig, the distribution was shifted to show most contigs' longest transcript was closer to the assembler threshold of 200 nucleotides. $\mathrm{H}-\mathrm{I}$. After filtering for transcripts with FPKM $\geq 1$, the distribution of transcripts in the assembly was distributed around 1,000 nucleotides $(H)$, which was roughly maintained after considering only the longest transcript per contig (I).

Additional file 2: Table S1. Assembly transcripts with best sense alignment per contig to D. rerio protein sequences (UniProt ID and accession), BLAST statistics, sequence coverage of target protein sequence, and description of $D$. rerio subject protein sequence.

Additional file 3: Table S2. Assembly transcripts with best alignment per contig to Actinopterygii protein sequences (UniProt ID and accession), BLAST statistics, sequence coverage of target protein sequence, and description of $D$. rerio subject protein sequence. Shown are only BLAST hits that covered $80 \%$ or more of the target protein sequence.

Additional file 4: Table S3. Significantly enriched GO terms based on FPKM ranking of "complete" transcripts ( $\geq 80 \%$ sequence coverage of homologous $D$. rerio protein), including genes enriched in each category, divided by cellular component, molecular function, and biological processes. ' $P$-value' is the enrichment $p$-value (unadjusted for multiple comparisons) computed according to the $\mathrm{mHG}$ or HG model. 'FDR q-value' is the multiple-testing corrected $\mathrm{p}$-value using the Benjamini and Hochberg method, whereby, for the $i^{\text {th }}$ term (ranked according to $p$-value) the FDR $q$-value is ( $p$-value * number of GO terms)/i. $N$ is the total number of genes, $B$ is the total number of genes associated with a specific $\mathrm{GO}$ term, $n$ is the number of genes in the top of the user's input list or in the target set when appropriate, and $b$ is the number of genes in the intersection. Enrichment $=(\mathrm{b} / \mathrm{n}) /(\mathrm{B} / \mathrm{N})$. For each $\mathrm{GO}$ term, the list is shown of associated genes that appear in the optimal top of the list as determined by GOrilla (with percent of gene list considered from minimum hypergeometric scoring threshold shown in 'Top\%' column). Each gene name is specified by gene symbol followed by a short description of the gene.

Additional file 5: Table S4. Assembly transcripts with best alignment/ gene to $D$. rerio ncRNA sequences, BLAST statistics, and sequence coverage of target ncRNA sequence. In general, alignments are sense, except where specified. Spreadsheet is divided into Kaushik et al. IncRNAs, antisense transcripts, lincRNA, mitochondrial rRNA, rRNA, SRP RNA, miRNA, snRNA, snoRNA, as well as, sense (intronic), sense (overlapping), and retained introns.

Additional file 6: Figure S2. ORF prediction. The distribution of ORF lengths chosen by TransDecoder was similar overall, regardless of whether or not Pfam domains were used for guiding ORF selection (A without Pfam-biased ORF selection, B with Pfam-biased ORF selection). Similarly, overall FPKM filtering had little effect on ORF size distribution without Pfam-biased ORF selection (C) or including Pfam-biased ORF selection (D). E. Venn diagram of ORFs (no Pfam) vs FPKM $\geq 1$ vs annotated protein coding transcripts (blastP). F. Venn diagram of ORFs (Pfam) vs. FPKM $\geq 1$ vs annotated protein coding transcripts (blastP). G. Venn diagram of all unique BLAST hits from $D$. rerio reference set compared with unique BLAST hits from the set of ORFs found in transcripts with FPKM $\geq 1$. H. Out of the 6,090 transcripts with FPKM $\geq 1$ that contained ORFs of over 100 amino acids and did not align to a D. rerio protein in our reference sequence set, 3,505 had significant alignments when BLASTp-searched against the entire NCBI non-redundant (nr) protein sequence database. 3,273 of these alignments were to sequences from Teleostei species. Shown are the ten most enriched species and the number of ORFs (log-scale) that were matched to each.

Additional file 7: Table S5. D. rerio reference proteins with two or more distinct assembly contig ORFs that align to greater than $80 \%$ of the target $D$. rerio sequence. $D$. rerio reference proteins are shown by their UniProt accession and name followed by the corresponding assembly contigs. For D. rerio proteins with exactly two aligned contigs, the percent identity of the assembly contig ORFs relative to each other is shown. Also included are the ORF nucleotide sequences for all contigs in this table (shown is ORF of transcript with longest alignment for each contig).

Additional file 8: Figure S3. Multiple ORFs align to uncharacterized $D$. rerio protein (A2BHKO). Little to no conservation was observed in the termini. Alignment performed with ClustalW2: * (asterisk) = fully conserved residue; : (colon) $=$ conservation between groups of strongly similar properties $(>0.5$, Gonnet PAM 250 matrix); . (period) = conservation between groups of weakly similar properties $(\leq 0.5)$.

Additional file 9: Table S6. Protein IDs from database containing all ORFs chosen by TransDecoder (any size) with Mascot-assigned protein families, Mascot statistics, sequence coverage based on peptide assignments, BLAST results to $D$. rerio reference proteins (if found), sequence coverage of alignments, and protein sequence of identified ORFs.

\section{Competing interests}

The authors declare that they have no competing interests.

\section{Authors' contributions}

JPS participated in the design of the study, performed the data analysis, sequence alignment, and drafted the manuscript. RFS participated in the design of the study, carried out the laboratory experimental work, and drafted the manuscript. BM participated in the data analysis. JRA participated in the design of the proteomics study and performed the LC-MS/MS analysis. JNA and GKHZ conceived the study, participated in its design and coordination, and helped in drafting the manuscript. All authors read and approved the final manuscript.

\section{Acknowledgements}

The authors would like to thank Dr. Michele A. Busby for helpful discussions regarding experimental design and data analysis, Jessica Henderson for assisting with data analysis, and Dr. Iulian Ilieş for helpful discussions. We would like to thank the PRIDE Team in providing a resource for sharing 
proteomics data. This work was supported by intramural funds provided by Northeastern University to JNA and GKHZ.

\section{Author details}

'Barnett Institute, Department of Chemistry and Chemical Biology, Northeastern University, 360 Huntington Avenue, 412 TF, Boston, MA 02115, USA. ${ }^{2}$ Laboratory of Neurobiology, Department of Biology, Northeastern University, 360 Huntington Avenue, 134 Mugar Life Sciences, Boston, MA 02115, USA. ${ }^{3}$ Department of Pharmaceutical Sciences, Northeastern University, 360 Huntington Avenue, 412 TF, Boston, MA 02115, USA.

\section{Received: 27 October 2014 Accepted: 18 February 2015}

\section{Published online: 11 March 2015}

\section{References}

1. Mehaffey WH, Fernandez FR, Rashid AJ, Dunn RJ, Turner RW. Distribution and function of potassium channels in the electrosensory lateral line lobe of weakly electric apteronotid fish. J Comp Physiol A. 2006;192:637-48.

2. Mehaffey WH, Ellis LD, Krahe R, Dunn RJ, Chacron MJ. Ionic and neuromodulatory regulation of burst discharge controls frequency tuning. J Physiol Paris. 2008;102:195-208.

3. Dye J. Dynamics and stimulus-dependence of pacemaker control during behavioral modulations in the weakly electric fish, Apteronotus. J Comp Physiol A. 1987;161:175-85.

4. Dye J. Ionic and synaptic mechanisms underlying a brainstem oscillator: an in vitro study of the pacemaker nucleus of Apteronotus. J Comp Physiol A. 1991;168:521-32.

5. Smith GT. Pharmacological characterization of ionic currents that regulate high-frequency spontaneous activity of electromotor neurons in the weakly electric fish, Apteronotus leptorhynchus. J Neurobiol. 2006;66:1-18.

6. Smith GT, Zakon HH. Pharmacological characterization of ionic currents that regulate the pacemaker rhythm in a weakly electric fish. J Neurobiol. 2000;42:270-86.

7. Hupé GJ, Lewis JE. Electrocommunication signals in free swimming brown ghost knifefish, Apteronotus leptorhynchus. J Exp Biol. 2008;211:1657-67.

8. Márquez BT, Krahe R, Chacron MJ. Neuromodulation of early electrosensory processing in gymnotiform weakly electric fish. J Exp Biol. 2013;216:2442-50

9. Sîrbulescu RF, Zupanc GKH. Spinal cord repair in regeneration-competent vertebrates: adult teleost fish as a model system. Brain Res Rev. 2011;67:73-93.

10. Zupanc GKH, Sîrbulescu RF. Teleost fish as a model system to study successful regeneration of the central nervous system. Curr Top Microbiol Immunol. 2013;367:193-233.

11. Bass AH. Electric organs revisited: evolution of a vertebrate communication and orientation organ. In: Bullock TH, Heiligenberg W, editors. Electroreception. New York: John Wiley; 1986. p. 13-70.

12. Chen L, House JL, Krahe R, Nelson ME. Modeling signal and background components of electrosensory scenes. J Comp Physiol A. 2005;191:331-45.

13. Fotowat $H$, Harrison RR, Krahe R. Statistics of the electrosensory input in the freely swimming weakly electric fish Apteronotus leptorhynchus. J Neurosci. 2013;33:13758-72.

14. Hagedorn M, Heiligenberg W. Court and spark: electric signals in the courtship and mating of gymnotoid fish. Anim Behav. 1985;33:254-65.

15. Engler G, Zupanc GKH. Differential production of chirping behavior evoked by electrical stimulation of the weakly electric fish, Apteronotus leptorhynchus. J Comp Physiol A. 2001;187:747-56.

16. Tallarovic SK, Zakon HH. Electrocommunication signals in female brown ghost electric knifefish, Apteronotus leptorhynchus. J Comp Physiol A. 2002;188:649-57.

17. Zupanc GKH, Sîrbulescu RF, Nichols A, llies I. Electric interactions through chirping behavior in the weakly electric fish, Apteronotus leptorhynchus. J Comp Physiol A. 2006;192:159-73.

18. Walz H, Hupé GJ, Benda J, Lewis JE. The neuroethology of electrocommunication: how signal background influences sensory encoding and behaviour in Apteronotus leptorhynchus. J Physiol Paris. 2013;107:13-25.

19. Cuddy M, Aubin-Horth N, Krahe R. Electrocommunication behaviour and non invasively-measured androgen changes following induced seasonal breeding in the weakly electric fish, Apteronotus leptorhynchus. Horm Behav. 2012;61:4-11.

20. Zakon HH. The electroreceptive periphery. In: Bullock TH, Heiligenberg W, editors. Electroreception. New York: John Wiley; 1986. p. 103-56.
21. Clarke SE, Longtin A, Maler L. A neural code for looming and receding motion is distributed over a population of electrosensory ON and OFF contrast cells. J Neurosci. 2014;34:5583-94.

22. Zupanc GKH, Bullock TH. From electrogenesis to electroreception: an overview. In: Bullock TH, Hopkins CD, Popper AN, Fay RR, editors. Electroreception. New York: Springer; 2005. p. 5-46.

23. Maler L, Sas E, Johnston S, Ellis W. An atlas of the brain of the electric fish Apteronotus leptorhynchus. J Chem Neuroanat. 1991;4:1-38.

24. Zupanc GKH, Horschke I. Proliferation zones in the brain of adult gymnotiform fish: a quantitative mapping study. J Comp Neurol. 1995:353:213-33.

25. Zupanc GKH. Adult neurogenesis in teleost fish. In: Seki T, Sawamoto K, Parent JM, Alvarez-Buylla A, editors. Neurogenesis in the Adult Brain, vol. 1. Tokyo: Springer; 2011. p. 137-68.

26. Sîrbulescu RF, Zupanc GKH. Neuronal regeneration. In: Evans DH, Claiborne JB, Currie S, editors. The Physiology of Fishes. Fourth ed. Boca Raton: CRC Press; 2013. p. 405-41.

27. Zupanc GKH, Hinsch K, Gage FH. Proliferation, migration, neuronal differentiation, and long-term survival of new cells in the adult zebrafish brain. J Comp Neurol. 2005;488:290-319.

28. Teles MC, Sîrbulescu RF, Wellbrock UM, Oliveira RF, Zupanc GKH. Adult neurogenesis in the brain of the Mozambique tilapia, Oreochromis mossambicus. J Comp Physiol A. 2012;198:427-49.

29. Zupanc GKH, Sîrbulescu RF, Ilieş I. Radial glia in the cerebellum of adult teleost fish: implications for the guidance of migrating new neurons. Neuroscience. 2012;210:416-30.

30. Sîrbulescu RF, llieş I, Zupanc GKH. Quantitative analysis reveals dominance of gliogenesis over neurogenesis in an adult brainstem oscillator. Dev Neurobiol. 2014;74:934-52.

31. Sîrbulescu RF, Ilieş I, Vitalo AG, Trull K, Zhu J, Traniello IM, et al. Adult stem cells in the knifefish cerebellum. Dev Neurobiol. 2015;75:39-65.

32. Hinsch K, Zupanc GKH. Isolation, cultivation, and differentiation of neural stem cells from adult fish brain. J Neurosci Methods. 2006;158:75-88.

33. Zupanc GKH, Horschke I, Ott R, Rascher GB. Postembryonic development of the cerebellum in gymnotiform fish. J Comp Neurol. 1996;370(4):443-64.

34. Traniello IM, Sîrbulescu RF, Ilieş I, Zupanc GKH. Age-related changes in stem cell dynamics, neurogenesis, apoptosis, and gliosis in the adult brain: a novel teleost fish model of negligible senescence. Dev Neurobiol. 2014;74:514-30.

35. Zupanc MM, Wellbrock UM, Zupanc GKH. Proteome analysis identifies novel protein candidates involved in regeneration of the cerebellum of teleost fish. Proteomics. 2006;6:677-96.

36. Ilieş I, Zupanc MM, Zupanc GKH. Proteome analysis reveals protein candidates involved in early stages of brain regeneration of teleost fish. Neuroscience. 2012;219:302-13.

37. Sîrbulescu RF, llieş I, Zupanc GKH. Structural and functional regeneration after spinal cord injury in the weakly electric teleost fish, Apteronotus leptorhynchus. J Comp Physiol A. 2009;195:699-714.

38. Sîrbulescu RF, Zupanc GKH. Inhibition of caspase-3-mediated apoptosis improves spinal cord repair in a regeneration-competent vertebrate system. Neuroscience. 2010;171:599-612.

39. Sîrbulescu RF, Zupanc GKH. Effect of temperature on spinal cord regeneration in the weakly electric fish, Apteronotus leptorhynchus. J Comp Physiol A. 2010;196:359-68

40. Allen AR, Smith GT. Spinal transection induces widespread proliferation of cells along the length of the spinal cord in a weakly electric fish. Brain Behav Evol. 2012;80:269-80.

41. Rashid AJ, Dunn RJ. Sequence diversity of voltage-gated potassium channels in an electric fish. Brain Res Mol Brain Res. 1998:54:101-7.

42. Rashid AJ, Morales E, Turner RW, Dunn RJ. The contribution of dendritic Kv3 $\mathrm{K}^{+}$channels to burst threshold in a sensory neuron. J Neurosci. 2001;21:125-35.

43. Bottai D, Dunn RJ, Ellis W, Maler L. N-methyl-D-aspartate receptor 1 mRNA distribution in the central nervous system of the weakly electric fish Apteronotus leptorhynchus. J Comp Neurol. 1997;389:65-80.

44. Bottai D, Maler L, Dunn RJ. Alternative RNA splicing of the NMDA receptor NR1 mRNA in the neurons of the teleost electrosensory system. J Neurosci. 1998;18:5191-202.

45. Harvey-Girard E, Dunn RJ. Excitatory amino acid receptors of the electrosensory system: the NR1/NR2B N-methyl-D-aspartate receptor. J Neurophysiol. 2003;89:822-32. 
46. Deng Q, Rashid AJ, Fernandez FR, Turner RW, Maler L, Dunn RJ. A C-terminal domain directs Kv3.3 channels to dendrites. J Neurosci. 2005;25:11531-41.

47. Oestreich J, Dembrow NC, George AA, Zakon HH. A "sample-and-hold" pulse-counting integrator as a mechanism for graded memory underlying sensorimotor adaptation. Neuron. 2006;49:577-88.

48. Ellis LD, Mehaffey WH, Harvey-Girard E, Turner RW, Maler L, Dunn RJ. SK channels provide a novel mechanism for the control of frequency tuning in electrosensory neurons. J Neurosci. 2007;27:9491-502.

49. Arnegard ME, Zwickl DJ, Lu Y, Zakon HH. Old gene duplication facilitates origin and diversification of an innovative communication system-twice. Proc Natl Acad Sci U S A. 2010;107:22172-7.

50. Harvey-Girard E, Dunn RJ, Maler L. Regulated expression of N-methyl-Daspartate receptors and associated proteins in teleost electrosensory system and telencephalon. J Comp Neurol. 2007;505:644-68.

51. Harvey-Girard E, Giassi AC, Ellis W, Maler L. Expression of the cannabinoid CB1 receptor in the gymnotiform fish brain and its implications for the organization of the teleost pallium. J Comp Neurol. 2013;521:949-75.

52. Zupanc GKH, Siehler S, Jones EM, Seuwen K, Furuta H, Hoyer D, et al. Molecular cloning and pharmacological characterization of a somatostatin receptor subtype in the gymnotiform fish Apteronotus albifrons. Gen Comp Endocrinol. 1999;115:333-45.

53. Siehler S, Zupanc GKH, Seuwen K, Hoyer D. Characterisation of the fish sst3 receptor, a member of the SRIF1 receptor family: atypical pharmacological features. Neuropharmacology. 1999;38:449-62.

54. Siehler S, Nunn C, Zupanc GKH, Hoyer D. Fish somatostatin sst3 receptor: comparison of radioligand and GTPgammaS binding, adenylate cyclase and phospholipase $\mathrm{C}$ activities reveals different agonist-dependent pharmacological signatures. Auton Autacoid Pharmacol. 2005;25:1-16.

55. Lee $S$, Maler L, Dunn RJ. Differential expression of the PSD-95 gene family in electrosensory neurons. J Comp Neurol. 2000;426:429-40.

56. Lariviere K, MacEachern L, Greco V, Majchrzak G, Chiu S, Drouin G, et al. $\mathrm{GAD}(65)$ and $\mathrm{GAD}(67)$ isoforms of the glutamic acid decarboxylase gene originated before the divergence of cartilaginous fishes. Mol Biol Evol. 2002;19:2325-9.

57. Crow KD, Amemiya CT, Roth J, Wagner GP. Hypermutability of HoxA13A and functional divergence from its paralog are associated with the origin of a novel developmental feature in zebrafish and related taxa (Cypriniformes). Evolution. 2009;63:1574-92

58. Aparicio S, Chapman J, Stupka E, Putnam N, Chia JM, Dehal P, et al. Whole-genome shotgun assembly and analysis of the genome of Fugu rubripes. Science. 2002:297:1301-10.

59. Jaillon O, Aury JM, Brunet F, Petit JL, Stange-Thomann N, Mauceli E, et al Genome duplication in the teleost fish Tetraodon nigroviridis reveals the early vertebrate proto-karyotype. Nature. 2004;431:946-57.

60. Kasahara M, Naruse K, Sasaki S, Nakatani Y, Qu W, Ahsan B, et al. The medaka draft genome and insights into vertebrate genome evolution. Nature. 2007;447:714-9.

61. Star B, Nederbragt AJ, Jentoft S, Grimholt U, Malmstrom M, Gregers TF, et al. The genome sequence of Atlantic cod reveals a unique immune system. Nature. 2011:477:207-10.

62. Jones FC, Grabherr MG, Chan YF, Russell P, Mauceli E, Johnson J, et al. The genomic basis of adaptive evolution in threespine sticklebacks. Nature. 2012;484:55-61.

63. Howe K, Clark MD, Torroja CF, Torrance J, Berthelot C, Muffato M, et al. The zebrafish reference genome sequence and its relationship to the human genome. Nature. 2013;496:498-503.

64. Schartl M, Walter RB, Shen Y, Garcia T, Catchen J, Amores A, et al. The genome of the platyfish, Xiphophorus maculatus, provides insights into evolutionary adaptation and several complex traits. Nat Genet. 2013:45:567-72

65. Amemiya CT, Alfoldi J, Lee AP, Fan S, Philippe H, Maccallum I, et al. The African coelacanth genome provides insights into tetrapod evolution. Nature. 2013;496:311-6.

66. Springer VG, Johnson GD. Study of the dorsal gill-arch musculature of teleostome fishes, with special reference to the Actinopterygii. Bull Biol Soc Wash. 2004;11:1-260

67. Nelson JS. Fishes of the World. 4th ed. Hoboken, New Jersey: John Wiley \& Sons; 2006

68. Haas BJ, Papanicolaou A, Yassour M, Grabherr M, Blood PD, Bowden J, et al De novo transcript sequence reconstruction from RNA-seq using the Trinity platform for reference generation and analysis. Nat Protoc. 2013;8:1494-512.
69. Del Fabbro C, Scalabrin S, Morgante M, Giorgi FM. An extensive evaluation of read trimming effects on Illumina NGS data analysis. PLoS One. 2013;8(12):e85024.

70. Juneja P, Osei-Poku J, Ho YS, Ariani CV, Palmer WJ, Pain A, et al. Assembly of the genome of the disease vector Aedes aegypti onto a genetic linkage map allows mapping of genes affecting disease transmission. PLoS Negl Trop Dis. 2014;8(1):e2652.

71. Cândido ED, Fernandes GD, de Alencar SA, Cardoso MHES, de Freitas Lima SM, Miranda VD, et al. Shedding some light over the floral metabolism by arum lily (Zantedeschia aethiopica) spathe de novo transcriptome assembly. PLoS One. 2014;9(3):e90487.

72. MacManes MD. On the optimal trimming of high-throughput mRNA sequence data. Front Genet. 2014;5:13.

73. Schunter C, Vollmer SV, Macpherson E, Pascual M. Transcriptome analyses and differential gene expression in a non-model fish species with alternative mating tactics. BMC Genomics. 2014;15:167.

74. Trapnell C, Roberts A, Goff L, Pertea G, Kim D, Kelley DR, et al. Differential gene and transcript expression analysis of RNA-seq experiments with TopHat and Cufflinks. Nat Protoc. 2012;7:562-78.

75. Francis WR, Christianson LM, Kiko R, Powers ML, Shaner NC SHDH. A comparison across non-model animals suggests an optimal sequencing depth for de novo transcriptome assembly. BMC Genomics. 2013;14:167.

76. Grabherr MG, Haas BJ, Yassour M, Levin JZ, Thompson DA, Amit I, et al. Full-length transcriptome assembly from RNA-Seq data without a reference genome. Nat Biotechnol. 2011;29:644-52.

77. Trapnell C, Williams BA, Pertea G, Mortazavi A, Kwan G, van Baren MJ, et al. Transcript assembly and quantification by RNA-Seq reveals unannotated transcripts and isoform switching during cell differentiation. Nat Biotechnol. 2010;28:511-5.

78. Haas BJ, Delcher AL, Mount SM, Wortman JR, Smith Jr RK, Hannick LI, et al. Improving the Arabidopsis genome annotation using maximal transcript alignment assemblies. Nucleic Acids Res. 2003;31:5654-66.

79. Mortazavi A, Williams BA, McCue K, Schaeffer L, Wold B. Mapping and quantifying mammalian transcriptomes by RNA-Seq. Nat Methods. 2008;5:621-8.

80. Gross JB, Furterer A, Carlson BM, Stahl BA. An integrated transcriptome-wide analysis of cave and surface dwelling Astyanax mexicanus. PLoS One. 2013:8:e55659.

81. Hinaux H, Poulain J, Da Silva C, Noirot C, Jeffery WR, Casane D, et al. De novo sequencing of Astyanax mexicanus surface fish and Pachón cavefish transcriptomes reveals enrichment of mutations in cavefish putative eye genes. PLoS One. 2013;8:e53553.

82. Diogo R, Doadrio I, Vandewalle P. Teleostean phylogeny based on osteological and myological characters. Int J Morphol. 2008;26:463-522.

83. Kanehisa M, Goto S. KEGG: kyoto encyclopedia of genes and genomes. Nucleic Acids Res. 2000;28:27-30.

84. Kanehisa M, Goto S, Sato Y, Kawashima M, Furumichi M, Tanabe M. Data, information, knowledge and principle: back to metabolism in KEGG. Nucleic Acids Res. 2014;42:D199-205.

85. Prykhozhij SV, Marsico A, Meijsing SH. Zebrafish Expression Ontology of Gene Sets (ZEOGS): a tool to analyze enrichment of zebrafish anatomica terms in large gene sets. Zebrafish. 2013;10:303-15.

86. Eden E, Navon R, Steinfeld I, Lipson D, Yakhini Z. GOrilla: a tool for discovery and visualization of enriched $\mathrm{GO}$ terms in ranked gene lists. BMC Bioinformatics. 2009;10:48.

87. Harvey-Girard E, Tweedle J, Ironstone J, Cuddy M, Ellis W, Maler L. Long-term recognition memory of individual conspecifics is associated with telencephalic expression of Egr-1 in the electric fish Apteronotus leptorhynchus. J Comp Neurol. 2010;518:2666-92

88. Harvey-Girard E, Giassi AC, Ellis W, Maler L. Organization of the gymnotiform fish pallium in relation to learning and memory: IV. Expression of conserved transcription factors and implications for the evolution of dorsal telencephalon. J Comp Neurol. 2012;520:3395-413.

89. Meza-Sosa KF, Valle-Garcia D, Pedraza-Alva G, Pérez-Martínez L. Role of microRNAs in central nervous system development and pathology. J Neurosci Res. 2012;90:1-12.

90. Morris KV, Mattick JS. The rise of regulatory RNA. Nat Rev Genet. 2014;15:423-37.

91. Clark BS, Blackshaw S. Long non-coding RNA-dependent transcriptional regulation in neuronal development and disease. Front Genet. 2014;5:164.

92. Zupanc GKH, Sîrbulescu RF. Adult neurogenesis and neuronal regeneration in the central nervous system of teleost fish. Eur J Neurosci. 2011;34:917-29. 
93. Kaushik K, Leonard VE, Kv S, Lalwani MK, Jalali S, Patowary A, et al. Dynamic expression of long non-coding RNAs (IncRNAs) in adult zebrafish. PLoS One. 2013;8:e83616.

94. Lagesen K, Hallin P, Rodland EA, Staerfeldt HH, Rognes T, Ussery DW. RNAmmer: consistent and rapid annotation of ribosomal RNA genes. Nucleic Acids Res. 2007:35:3100-8.

95. Barboric M, Lenasi T, Chen H, Johansen EB, Guo S, Peterlin BM. 7SK snRNP/P-TEFb couples transcription elongation with alternative splicing and is essential for vertebrate development. Proc Natl Acad Sci U S A. 2009;106:7798-803.

96. Aviram N, Schuldiner M. Embracing the void-how much do we really know about targeting and translocation to the endoplasmic reticulum? Curr Opin Cell Biol. 2014;29C:8-17.

97. Kampmann M, Blobel G. Biochemistry. Nascent proteins caught in the act. Science. 2009:326:1352-3.

98. Mercer TR, Dinger ME, Sunkin SM, Mehler MF, Mattick JS. Specific expression of long noncoding RNAs in the mouse brain. Proc Natl Acad Sci U S A. 2008; 105:716-21.

99. Ling MH, Ban Y, Wen H, Wang SM, Ge SX. Conserved expression of natural antisense transcripts in mammals. BMC Genomics. 2013;14:243.

100. Finn RD, Mistry J, Schuster-Bockler B, Griffiths-Jones S, Hollich V, Lassmann T, et al. Pfam: clans, web tools and services. Nucleic Acids Res. 2006;34:D247-51.

101. Colomer J, Means AR. Physiological roles of the $\mathrm{Ca}^{2+} / \mathrm{CaM}$-dependent protein kinase cascade in health and disease. Subcell Biochem. 2007:45:169-214.

102. Wisniewski JR, Zougman A, Nagaraj N, Mann M. Universal sample preparation method for proteome analysis. Nat Methods. 2009;6(5):359-62

103. Erde J, Loo RR, Loo JA. Enhanced FASP (eFASP) to increase proteome coverage and sample recovery for quantitative proteomic experiments. J Proteome Res. 2014;13:1885-95.

104. Perkins DN, Pappin DJC, Creasy DM, Cottrell JS. Probability-based protein identification by searching sequence databases using mass spectrometry data. Electrophoresis. 1999;20(18):3551-67.

105. Sheynkman GM, Shortreed MR, Frey BL, Scalf M, Smith LM. Large-scale mass spectrometric detection of variant peptides resulting from nonsynonymous nucleotide differences. J Proteome Res. 2014;13:228-40.

106. Borodina T, Adjaye J, Sultan M. A strand-specific library preparation protocol for RNA sequencing. Methods Enzymol. 2011;500:79-98.

107. Lohse M, Bolger AM, Nagel A, Fernie AR, Lunn JE, Stitt M, et al. RobiNA: a user-friendly, integrated software solution for RNA-Seq-based transcriptomics. Nucleic Acids Res. 2012;40:W622-7.

108. Flicek P, Amode MR, Barrell D, Beal K, Billis K, Brent S, et al. Ensembl 2014. Nucleic Acids Res. 2014;42:D749-55.

109. Guttman M, Amit I, Garber M, French C, Lin MF, Feldser D, et al. Chromatin signature reveals over a thousand highly conserved large non-coding RNAs in mammals. Nature. 2009;458:223-7.

110. Finn RD, Clements J, Eddy SR. HMMER web server: interactive sequence similarity searching. Nucleic Acids Res. 2011;39:W29-37.

111. Li B, Dewey CN. RSEM: accurate transcript quantification from RNA-Seq data with or without a reference genome. BMC Bioinformatics. 2011;12:323.

112. Zhang B, Kirov S, Snoddy J. WebGestalt: an integrated system for exploring gene sets in various biological contexts. Nucleic Acids Res. 2005;33:W741-8.

113. Wang J, Duncan D, Shi Z, Zhang B. WEB-based GEne SeT AnaLysis Toolkit (WebGestalt): update 2013. Nucleic Acids Res. 2013;41:W77-83.

114. Eden E, Lipson D, Yogev S, Yakhini Z. Discovering motifs in ranked lists of DNA sequences. PLoS Comput Biol. 2007;3:e39.

115. Jantzen SG, Sutherland BJ, Minkley DR, Koop BF. GO Trimming: Systematically reducing redundancy in large Gene Ontology datasets. BMC Res Notes. 2011:4:267.

116. Supek F, Bosnjak M, Skunca N, Smuc T. REVIGO summarizes and visualizes long lists of gene ontology terms. PLoS One. 2011;6:e21800.

117. Shevchenko A, Tomas H, Havlis J, Olsen JV, Mann M. In-gel digestion for mass spectrometric characterization of proteins and proteomes. Nat Protoc. 2006;1:2856-60.

118. Punta M, Coggill PC, Eberhardt RY, Mistry J, Tate J, Boursnell C, et al. The Pfam protein families database. Nucleic Acids Res. 2012;40:D290-301.

119. Johnson LS, Eddy SR, Portugaly E. Hidden Markov model speed heuristic and iterative HMM search procedure. BMC Bioinformatics. 2010;11:431.
120. Eddy SR. Accelerated Profile HMM Searches. PLoS Comput Biol. 2011;7:e1002195.

121. Vizcaino JA, Deutsch EW, Wang R, Csordas A, Reisinger F, Rios D, et al. ProteomeXchange provides globally coordinated proteomics data submission and dissemination. Nat Biotechnol. 2014;32(3):223-6.

122. Vizcaino JA, Cote RG, Csordas A, Dianes JA, Fabregat A, Foster JM, et al. The PRoteomics IDEntifications (PRIDE) database and associated tools: status in 2013. Nucleic Acids Res. 2013;41(Database issue):D1063-9.

\section{Submit your next manuscript to BioMed Central and take full advantage of:}

- Convenient online submission

- Thorough peer review

- No space constraints or color figure charges

- Immediate publication on acceptance

- Inclusion in PubMed, CAS, Scopus and Google Scholar

- Research which is freely available for redistribution 